\title{
Economic uncertainty and its impact on the Croatian economy
}

\author{
PETAR SORIĆ, Ph.D.* \\ IVANA LOLIĆ, univ. spec. oec.*
}

Article**

JEL: E03, E32, E61

doi: $10.3326 /$ pse. 41.4 .3

\footnotetext{
* The authors thank two anonymous reviewers for their valuable comments, which have considerably improved the overall quality of the paper. This work has been partially supported by the Croatian Science Foundation under project No. 3858.

** Received: June 1, 2017

Accepted: October 30, 2017
}

The article was submitted for the 2017 annual award of the Prof. Dr. Marijan Hanžeković Prize.

\section{Petar SORIĆ}

University of Zagreb, Faculty of Economics and Business Zagreb, Trg J.F. Kennedyja 6, Zagreb, Croatia e-mail: psoric@efzg.hr

ORCiD: 0000-0002-6773-264X

Ivana LOLIĆ

University of Zagreb, Faculty of Economics and Business Zagreb, Trg J.F. Kennedyja 6, Zagreb, Croatia e-mail: ilolic@efzg.hr ORCiD: 0000-0003-3112-7699 


\title{
Abstract
}

The aim of this paper is to quantify institutional (political and fiscal) and noninstitutional uncertainty (economic policy uncertainty, Economists' recession index, natural disasters-related uncertainty, and several disagreement measures). The stated indicators are based on articles from highly popular Croatian news portals, the repository of law amendments (Narodne novine), and Business and Consumer Surveys. We also introduce a composite uncertainty indicator, obtained by the principal components method. The analysis of a structural VAR model of the Croatian economy (both with fixed and time-varying parameters) has showed that a vast part of the analysed indicators are significant predictors of economic activity. It is demonstrated that their impact on industrial production is the strongest in the onset of a crisis. On the other hand, the influence of fiscal uncertainty exhibits just the opposite tendencies. It strengthens with the intensification of economic activity, which partially exculpates the possible utilization of fiscal expansion as a counter-crisis tool.

Keywords: economic uncertainty, Economic Policy Uncertainty Index, VAR model with time-varying parameters

\begin{abstract}
"The only relevant thing is uncertainty - the extent of our own knowledge and ignorance. The actual fact of whether or not the events considered are in some sense determined, or known by other people, and so on, is of no consequence."
\end{abstract}

De Finetti, 1975:vi

\section{INTRODUCTION}

The collapse of Lehman Brothers and the downturn of the US economy in 2008 triggered a domino effect of spillovers on almost all of the world's national economies. The crisis affected some countries only marginally (e.g. Poland and Slovakia), and some European countries recovered from the global shock in relatively short periods (Germany, Austria, Benelux countries), while the crisis in Croatia proved to be extremely resilient and long lasting. Two years passed from the evident onset of the crisis in Q3 2008 (Krznar, 2011) to the first transition of GDP growth to the positive domain. However, the positive shift was only short-lived. A double dip recession became evident in Q4 2011, followed by as many as 12 consecutive quarters of declining economic activity. This negative streak was one of the longest recessions in the whole of Europe (Buturac, 2017:23) and has triggered an entire series of domestic studies.

Croatian economic practitioners and academics mostly agree that the crisis was the multi-layered consequence of numerous factors. Many authors (from several scientific disciplines) have referred to the demographic issues, the meta-determinants of weak competitiveness such as the egalitarian syndrome (Burić and Štulhofer, 2016), the (too) high levels of public debt (Buturac, 2017), etc. How- 
ever, the international literature also offers relevant evidence on the considerable influence of uncertainty on the decreased economic activity during the recent crisis (Bloom, 2009; Bachmann, Elstner and Sims, 2013; Baker, Bloom and Davis, 2016, etc.). These studies are (with rare exceptions such as Arčabić, 2015) not followed by corresponding analysis for the Croatian economy. Therefore, a question is raised: to what extent can the longevity and intensity of the recent Croatian economic crisis be attributed to uncertainty itself? That is the main research question of this paper, and its basic contribution to the literature.

This paper introduces an entire set of uncertainty indicators to the Croatian practice of economic research: political uncertainty, recession-related uncertainty (The Economist, 2002), fiscal uncertainty resulting from changes of fiscal legislation, uncertainty stemming from natural disasters and a Croatian version of the Baker, Bloom and Davis (2016) economic policy uncertainty index. We also consider indicators of prognostic disagreement (following Bachmann, Elstner and Sims, 2013) as proxy variables for economic uncertainty. Additionally, we employ the principle components method to generate a composite indicator of aggregate uncertainty as a linear combination of the previously stated variables.

The second specificity of this paper is the interdisciplinary approach used to elucidate the macroeconomic phenomenon of recession by utilizing the psychological concept of uncertainty (while controlling for other relevant micro- and macroeconomic predictors of economic activity). The third contribution to the literature is the analysis of the potentially time-varying influence of uncertainty on economic activity, for previous papers have found that uncertainty is counter-cyclical (in the sense of correlation; Bloom, 2014), but do not analyse whether the uncertainty effect is different in various phases of the economic cycle. This paper employs a VAR model with time-variable parameters (Primiceri, 2005; del Negro and Primiceri, 2015) to test the hypothesis that economic activity is more responsive to uncertainty (in terms of the impulse response function) in a recession than in the expansionary phase of the economic cycle.

The econometric analysis has shown that the observed uncertainty measures on average have a significant, but only temporary effect on economic activity. Such an inference regarding the negative short-run relationship between uncertainty and economic activity is quite robust to several alternative model specifications (structural VAR model with fixed parameters, the inclusion of foreign variables due to the fact that Croatia is a small open economy, and alternation of the control variables in the VAR model with time-varying parameters). Nevertheless, we show that the negative impact of most of the uncertainty measures employed becomes more pronounced in the contractionary phase of the cycle.

The remainder of the paper is structured as follows. Section 2 presents the main theoretical considerations of the relationship between uncertainty and economic activity and an overview of the empirical approaches to uncertainty quantification. 
Section 3 deals with the data and methodological issues. Section 4 lays out the obtained econometric results, while the final section synthesizes the paper and sums up the main policy implications.

\section{THEORETICAL CONCEPTS OF THE INTERRELATIONSHIP BETWEEN UNCERTAINTY AND THE REAL ECONOMY}

The term uncertainty was introduced to the literature through a famous book by Frank Knight (1921), resulting in the concept nowadays often being referred to as Knightian uncertainty. The concept implies a situation in which economic agents are not able to anticipate future events or estimate the likelihood of their occurrence. Although uncertainty per se is a latent variable, the channels of its influence on economic activity are well elaborated in the literature.

The most meticulous overview to date of theoretical frameworks describing the uncertainty-economic activity link is presented by Bloom (2014). Arčabić (2015) is a rare example of the genre among the domestic Croatian authors. The two stated authors emphasize two negative, but also two positive transmission channels of uncertainty.

Bernanke (1983) introduces the first negative channel, and Bloom (2014) later on refers to it as the real options channel. Firms faced with uncertainty postpone their irreversible decisions in order to enrich their information set and reduce the uncertainty related to making such decisions. Therefore, the wait and see mechanism (Bachmann and Bayer, 2013) is activated because activities such as investments, employment, and buying durable goods generate certain sunk costs. Consumers can also activate the exact same mechanisms in the sense of postponing the consumption of durable goods or investing in financial assets.

It should also be highlighted that there are four conditions under which the real options channel is efficient (Bloom, 2014:163-164): (i) the existence of considerable adjustment costs and irreversible decisions, (ii) the possibility of postponing decisions (partially or completely eliminated by perfect competition), (iii) firms operating in imperfectly competitive markets with decreasing returns to scale, and (iv) uncertainty should be variable (not constant).

The second channel of influence is risk aversion. In a corporative sense, growth in uncertainty increases the risk premium and increases the cost of borrowing. It also discourages the company's management from taking part in risky endeavours (especially if the management has shares in the company), and it ultimately decreases the aggregate investments and the overall economic activity. In the consumer sector, risk aversion is effectuated through precautionary savings, which again decreases personal consumption and consequently lowers GDP (Carroll, 1992).

The two positive transmission channels are the growth options and the Oi-Hartman-Abel effect. The first one is the antipode to the real options channel, relating 
to the fact that uncertainty can also be an incentive for risky investments in situations of high potential gain (e.g. the global economic growth due to the Internet revolution, the so-called dot-com boom in the second half of the 1990s). The Oi-Hartman-Abel effect is based on hedging against negative business results, or situations in which the potential gain from a positive outcome considerably surpasses the potential losses from bad business results. In such scenarios, firms often tend to be risk-seeking and to take part in new investments.

The existing empirical findings offer far more evidence in favour of the negative influences of uncertainty (see Bloom (2014) for an excellent literature review), so it remains to be seen if the same will be corroborated for the Croatian economy.

The latent character of uncertainty has conditioned the fact that it was empirically treated only descriptively until the global financial crisis in 2008. The prevailing turbulent economic conditions in 2008 triggered several methodological strands in the quantification of economic uncertainty. Their basic principles will be presented in the following subsections.

\subsection{BAKER BLOOM DAVIS INDEX OF ECONOMIC POLICY UNCERTAINTY}

Prompted by the hypothesis that uncertainty is one of the major causes of such an atypically long and strong recession of the US economy after the Lehman Brothers bankruptcy, Baker, Bloom and Davis (2012) published their index of economic policy uncertainty (EPU index). The index is based on three pillars. The first is the archive of media news reports on economic uncertainty from 10 leading US newspapers. Searching through that archive using specific keyword combinations (e.g. economic + uncertainty/uncertain + congress/deficit/legislation, etc.) enabled Baker, Bloom and Davis (2012) to publish a scaled measure of monthly frequencies of articles dealing with economic uncertainty in the US.

As the second pillar of their index, the authors establish the number of federal tax code provisions expiring in the following 10 years.

The last EPU pillar is a disagreement measure based on the responses from the Survey of Professional Forecasters (SPF). To be specific, the authors use disagreement in forecasts of the consumer price index and the purchases of goods and services by the federal/state/local governments. The final estimate of EPU index is obtained each month by attaching a specific weight to each EPU component. A $1 / 2$ weight is attached to the media index of economic uncertainty, and a $1 / 6$ is attached to the expiring tax code provisions, price level disagreement, and government purchases.

The US public has mostly perceived the EPU index as a republican criticism of the Obama administration. However, it has also drawn the attention of researchers from various scientific fields. Baker, Bloom and Davis (2016) published a revised version of their research on uncertainty, showing that it affects the micro level 
through higher stock price volatility on the US market. This effect (analysed through panel regressions) is shown to be particularly strong in companies closely tied to the government (defence sector, health care, and the construction sector).

The authors also use VAR modelling to show that the macro effects are very similar. Uncertainty reduces investments, employment levels in US companies, and US industrial production. The exposed conclusions are corroborated using various robustness checks and adding different control variables, and are also confirmed by a panel VAR model comprising 12 world economies that have had their own versions of the EPU index at the time.

It is also worth mentioning Karnizova and $\mathrm{Li}$ (2014), who confirm the predictive characteristics of EPU in forecasting the US recessionary episodes; while Ajmi et al. (2015) point to the existence of (bi-directional) Granger causality between EPU and the US stock market yields.

Considering the strong evidence of the significant influence of EPU index on the US economic activity, one of the goals of this paper is to quantify the Croatian version of a media-based uncertainty index, and scrutinize if it is characterized by the same effects as that for the USA.

\subsection{THE ECONOMIST'S RECESSION INDEX}

The Economist has conceptualized its R-word (recession) index as early as the beginning of the 2000s (The Economist, 2002). This indicator is based on the quarterly frequency of recession-related articles in the Washington Post and New York Times. The index witnessed its full affirmation in the scientific sense only with the onset of the global financial crisis, when it started to be calculated and published in other countries as well as the USA. For example, Grossarth-Maticek and Mayr (2008) point to the significance of the R-word index in dating the German business cycle by a probit regression model. Iselin and Siliverstovs (2013) employ the autoregressive-distributed lag (ARDL) models of Swiss GDP, using the R-word index as the independent variable in the model. By doing so, they increase the predictive accuracy of simple univariate benchmark models. Iselin and Siliverstovs (2016) provide very similar results for Switzerland, while the same models for the German economy show to be less precise.

Considering the well-known fact that aggregate economic uncertainty is considerably higher in recessions (in comparison to the stable growth periods) (Bloom, 2009; 2014), the R-word index can also be viewed as a particular type of an uncertainty indicator. Since Croatia has not yet seen its own version of the R-word index, it will be interesting to quantify one and analyse its influence on the Croatian economic activity, and this will be carried out in the remainder of the paper. 
Bachmann, Elstner and Sims (2013) provide a follow-up on the third element of the EPU index, and postulate that uncertainty can be proxied by the degree of disagreement among economic forecasters. Their basic premise is that, in times of high uncertainty, the respondents in SPF would give remarkably heterogeneous answers to the questions focused on relevant variables from their economic surroundings. However, a high level of response dispersion does not necessarily need to imply high uncertainty. That is the reason why some authors insist on a clear distinction between the terms disagreement and uncertainty in the classical Knightian sense (Jurado, Ludvigson and Ng, 2015; Krüger and Nolte, 2016).

In the context of this paper, four separate indicators of disagreement are considered as proxy variables for economic uncertainty. All of them are based on the data from regular monthly Business and Consumer Surveys (BCS), published by the European Commission. The first indicator relates to consumers' disagreements on future tendencies of the general economic situation in Croatia. The second and third indicators reflect the uncertainty of consumer expectations of future unemployment and the timeliness of buying permanent goods. The fourth indicator is a disagreement measure stemming from all forward-looking questions in BCS. All four stated indicators will be explained in more detail in section 3.1.

Bachmann, Elstner and Sims (2013) use the described methodology to show that (ex ante) prognostic disagreement, just as the ex post prognostic errors of economic agents, considerably reduce economic activity in the short run (measured by industrial production, working hours, and employment level). Their results for the US turn out to be more significant than those for the German economy.

\subsection{ALTERNATIVE EMPIRICAL APPROACHES}

Apart from the widely recognized uncertainty measures (which might be valid for any analysed economy), one should also take into account the specificities of posttransition economies such as Croatia. Bloom (2014:162) emphasizes three specific uncertainty sources in economic systems of that type. First of all, they are often exposed to remarkable political instabilities and international conflicts. Due to their lower level of socio-economic development and insufficient infrastructure, they are also more prone to natural disasters such as floods or epidemics. The third group of relevant uncertainty drivers stems from the inefficient channels of fiscal and monetary policy.

In the last two decades, Croatia has not witnessed a coup d'état or a war, but the Croatian form of crony capitalism has revealed the link between the state and economic activity as a very important one. The elections play a particularly important role in generating political uncertainty (Mačkić, 2014) (especially with regards to the repeated parliamentary elections in September 2016 after only 10 months of the Orešković' government). Other sources of political uncertainty include the prevailing perception of public companies as the spoils of politics as well as an entire series of corruption scandals related to prominent political officials. 
Natural disasters also seem to be potentially relevant for the Croatian disasters, especially considering the dependency of agricultural production on the weather conditions, such as droughts and hailstorms, as well as floods, like those in Eastern Slavonia in May 2014.

Considering the continuity of Croatian monetary policy in employing the kuna/ euro exchange rate as the nominal anchor for maintaining price stability, we postulate that monetary uncertainty (if there is any at all) is not relevant in Croatia, and will not be examined here. ${ }^{1}$ On the other hand, fiscal uncertainty in Croatia is a problem that was recognized a long time ago (Bejaković, 2009).

The three stated uncertainty sources (political instability, natural disasters and fiscal instability) will be scrutinized in the following sections, along with their corresponding quantitative uncertainty indicators.

\section{DATA AND METHODOLOGY}

This section presents a brief overview of the analysed uncertainty indicators (as well as the other examined macroeconomic variables). The methodological basis of the utilized structural VAR models (with fixed and time-varying parameters) is presented afterwards.

\subsection{DATA}

The main methodological innovation of this paper is the introduction of several uncertainty indicators that have so far not been considered for the Croatian economy. To be specific, four monthly media-based indicators are formed: Baker Bloom Davis index $(B B D)^{2}$, political uncertainty index (polit), the R-word index ( $R$ _index), and an indicator of uncertainty related to natural disasters (nature). With the goal of quantifying the named indicators, we formed a database of media articles from the Internet archives of the most read Croatian news portals: Jutarnji list, Večernji list, 24sata, index.hr, dnevnik.hr, and Poslovni dnevnik. Besides the fact that these are the most popular Croatian daily newspapers, their web portals are regularly among the most visited of all Croatian web sites (Gemius Audience, 2017). Further on, these are (to the best of the authors' knowledge), the only news portals to have a coherent article archive without the breaks constituted by methodological changes. It is, therefore, reasonable to conclude that the described database will serve its purpose as the foundation for quantifying mediabased economic uncertainty in Croatia. The database comprises articles dating from November 2002 to December 2016, but each of the six examined web portals has its own starting date. Finally, the database comprises 1,030,768 articles for

\footnotetext{
${ }^{1}$ The readers may consult Governor Vujčić's frequent public presentations (e.g. Vujčić, 2016a; b) as indications of the strict focus on the stability of the HRK/EUR exchange rate.

${ }^{2}$ The Croatian version of the $B B D$ index, as suggested in this paper, is founded solely on the media reports on uncertainty. The uncertainty stemming from tax changes will be evaluated separately, just as the influence of forecasting disagreement (quantified through equation 1) on economic activity, will be treated separately. Therefore, a separate label is introduced for the Baker Bloom Davis index $(B B D)$, different from the US EPU index, comprising all three original components.
} 

disasters index, and 77,843 for the R-word index.

Using Structured Query Language (SQL), we search the database by pre-formulated combinations of keywords, different for each uncertainty indicator. A detailed list of keywords is given in appendix 1. For example, an article enters the quantification of $B B D$ index if it contains at least one of the keywords in part (a) of appendix 1 (e.g. economy, economic, etc.), at the same time at least one of the words in column "Logical conjunction I" (e.g. minister, prime minister), and some of the words from column "Logical conjunction II" (e.g. uncertainty, uncertain, etc.). The same logic (with the complete list of keywords given in appendix 1) is also applied for the polit ${ }^{3}, R_{-}$index and nature indicators. After separating the articles that satisfy the stated criteria, we formed the monthly relative frequencies (number of extracted articles divided by the number of total articles). The obtained results for each individual web portal are then standardized (in accordance with Baker, Bloom and Davis (2016) and Girardi and Reuter (2016) and averaged by months.

The fifth analysed uncertainty indicator refers to changes in fiscal legislation. To quantify it, we again use SQL to filter the legal acts from the web repository of law amendments (Narodne novine). The keywords utilized for this purpose are also given in appendix 1. From the total set of law acts containing the term "tax" in their title, we exclude those acts concerning the appointment or dismissal of officials in the Government or the Tax Administration, as well as specific changes in the tax rulebooks valid at the municipality/city/county level. Out of the total 49,749 legal acts, we extracted 298 "true" tax changes. In this specific case, we did not form the uncertainty indicator out of the obtained monthly frequencies of tax changes since a considerable number of months did not see any law changes at all (satisfying the adopted criteria). The intensity of the influence of a particular law change (in the sense of (un)certainty) is the strongest immediately before and after its passing and publication in Narodne novine. To account for that, we form a 6-months cumulative ( 3 months before and 3 months after the passing of a law) of the number of tax changes (PI6), and the econometric analysis is continued with that indicator. ${ }^{4}$

The basic five indicators analysed in this paper are presented in graphs 1-5. The BBD index shows a below average level of uncertainty right until the onset of the 2008 crisis, followed by an obvious, considerable and long lasting increase of uncertainty in the economic system.

\footnotetext{
${ }^{3}$ It should be noted that the list of keywords for the polit indicator does not comprise the terms "country prefect", "mayor", etc. The authors' intention was to extract only those political shocks that might significantly influence the Croatian macroeconomic tendencies. Following that approach, our analysis did not include (inter alia) the corruption scandals related to local potentates like the mayors Vlahović (Dubrovnik), Sabo (Vukovar) or Bandić (Zagreb), and the local prefect Lovrić Merzel (Sisačko-Moslavačka County).

${ }^{4}$ The results are very similar if a 4-month or 8-month cumulative is chosen.
} 


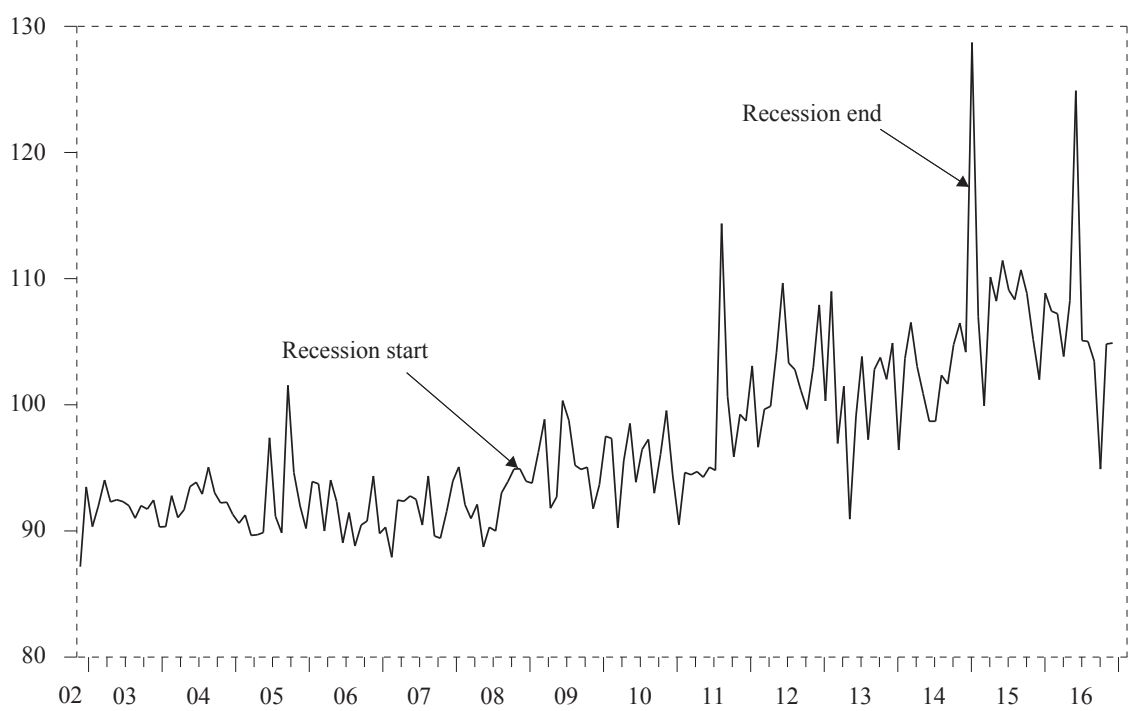

Source: Authors' calculations.

\section{GraPH 2}

Political uncertainty index

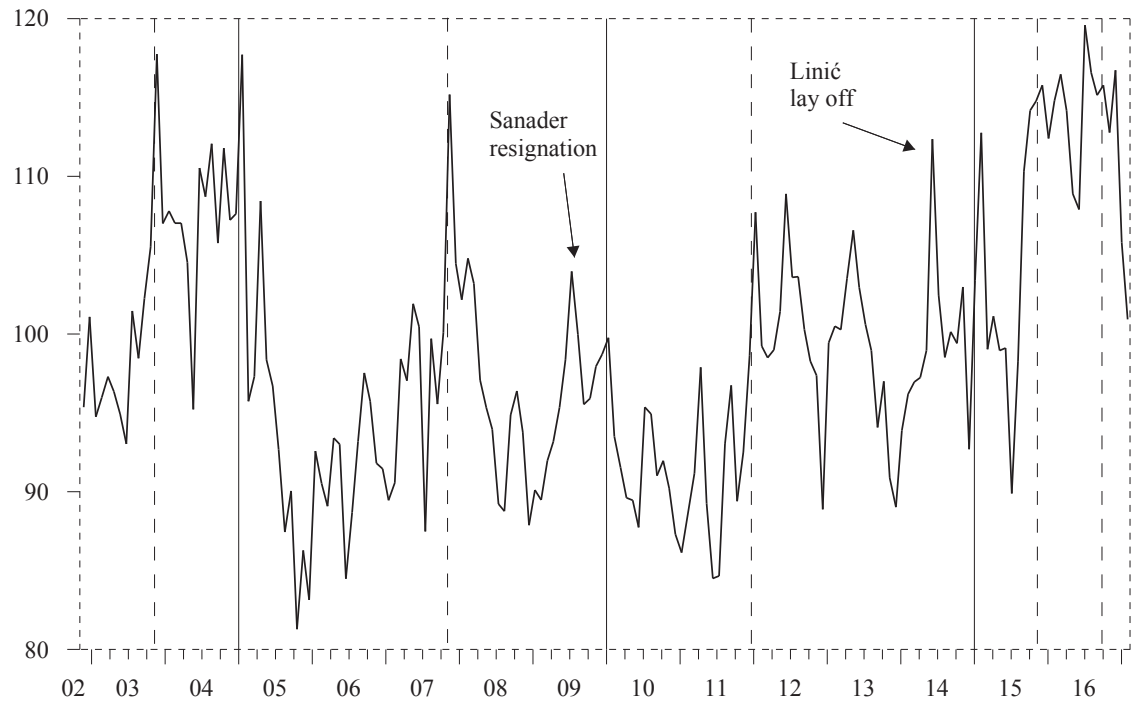

Note: Dotted lines point to the dates of parliamentary elections, while full lines point to presidential elections.

Source: Authors'calculations.

Graph 2 vividly shows that the local maxima of political uncertainty correspond to the pre-election campaigns (related to parliamentary or presidential elections). Therefore, political uncertainty cycles mostly coincide with the electoral cycles. Rare exceptions from that regularity are the political shocks like the resignation of 
former prime-minister Ivo Sanader in July 2009 and the reconstruction of Milanović's government (Slavko Linić lay off in May 2014 and the changes of ministers Jovanović-Mornar and Ostojić-Varga one month later).

\section{GraPh 3}

The R-word index

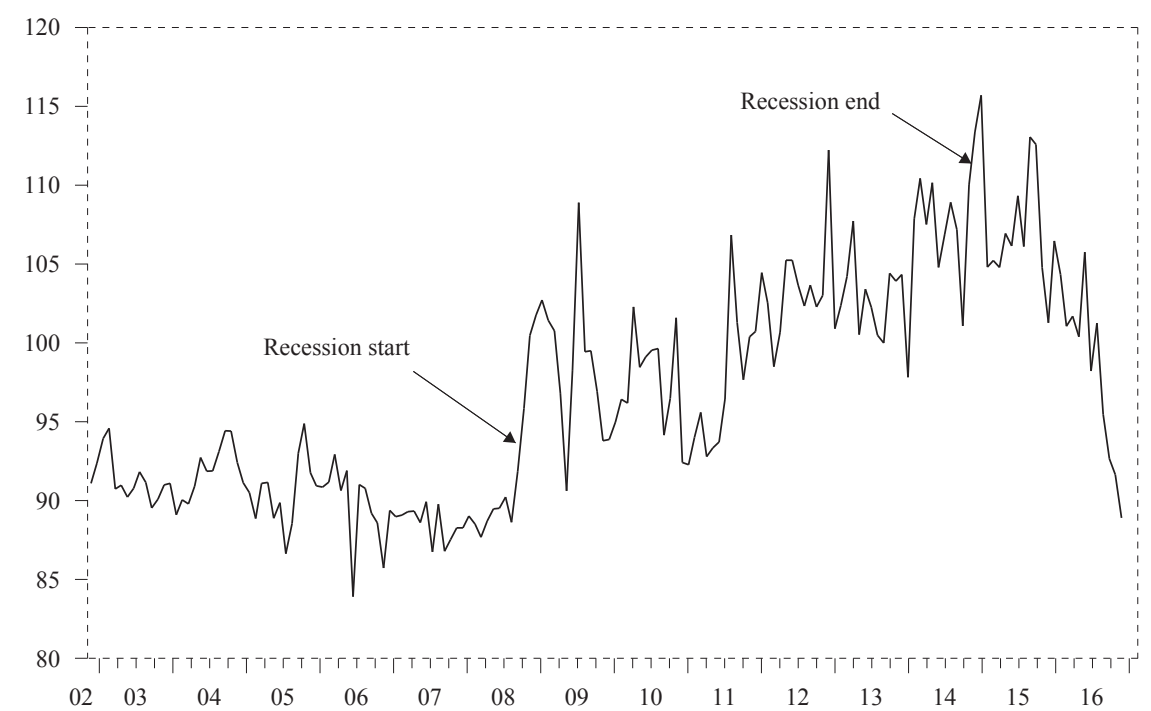

Source: Authors'calculations.

The R-word index graphically looks very similar to the $B B D$ index, presenting a cyclical match between economic activity and uncertainty.

\section{GraPH 4}

Natural disaster uncertainty index

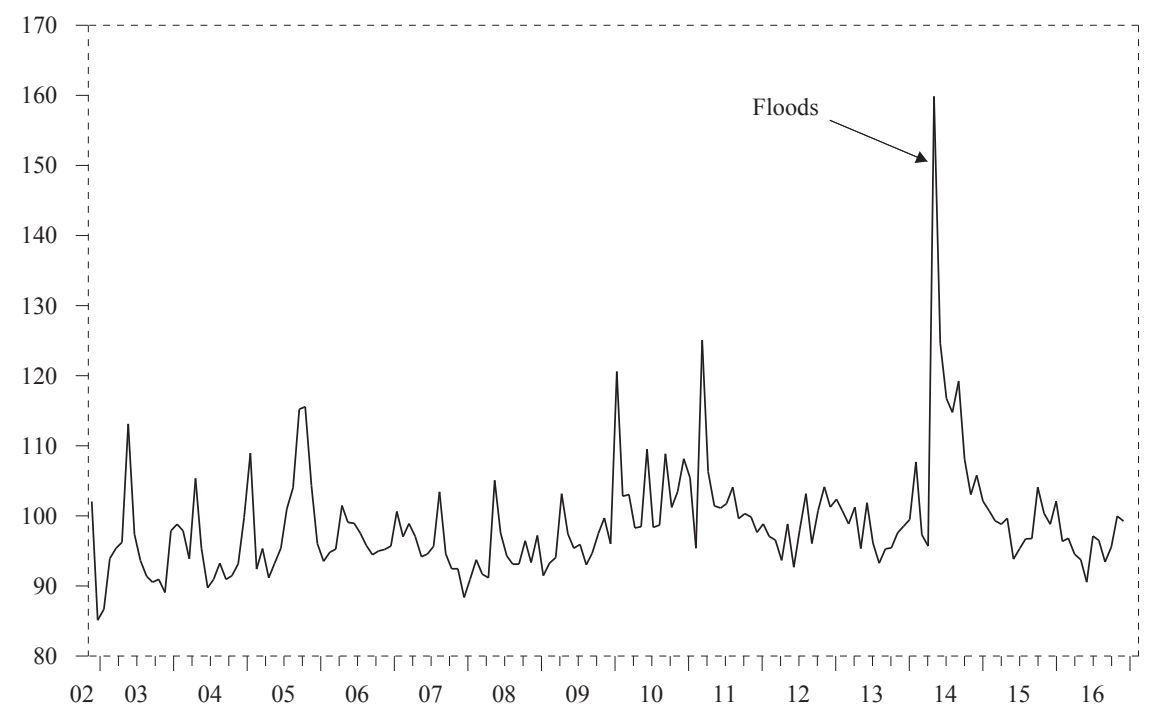

Source: Authors'calculations. 
The indicator of natural disaster-related uncertainty is characterized by a remarkable low-level stability. Practically one single shock is recorded, corresponding to the floods in Eastern Slavonia in May 2014.

\section{Graph 5}

Fiscal uncertainty indicator

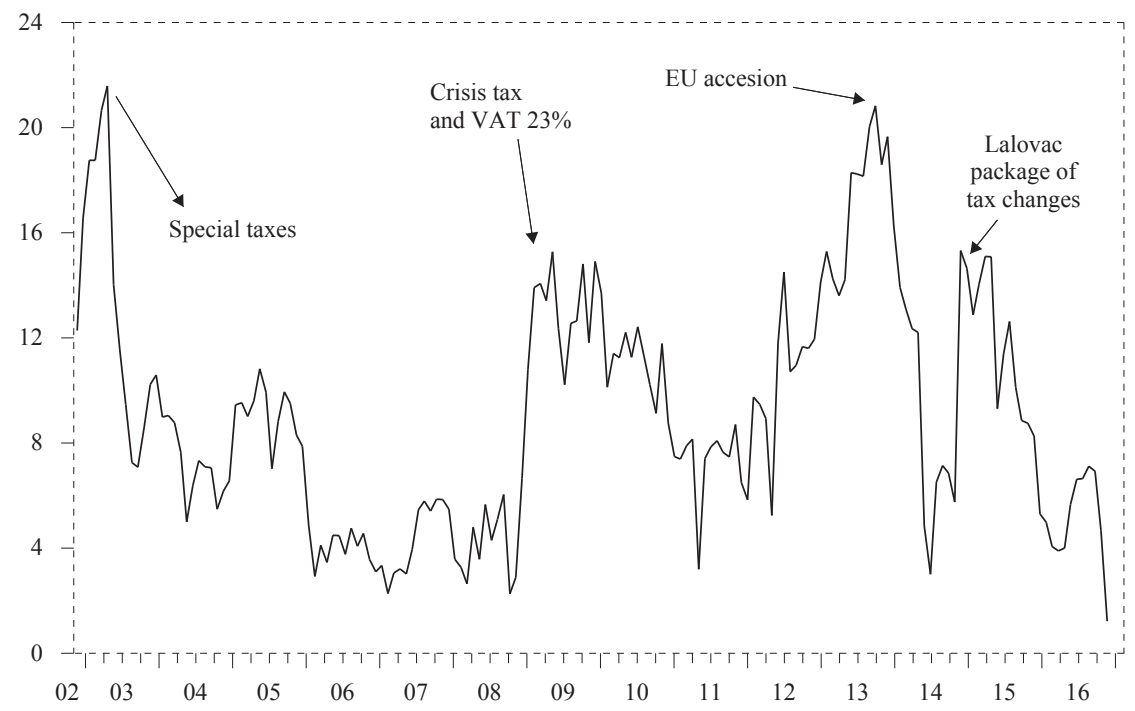

Source: Authors'calculations.

Graph 5 identifies four extreme increases of fiscal uncertainty. The first one occurred in late 2002, when a series of special tax (on tobacco products, personal vehicles, oil derivates, non-alcoholic beverages, luxury products, etc.) laws was passed. The other one refers to the introduction of the "crisis tax" and the increase of the VAT tax rate from $22 \%$ to $23 \%$. The third and the most intensive uncertainty shock happened in 2013 when, apart from the harmonisation of domestic fiscal legislation with EU regulations, a series of VAT, income tax and profit tax changes was also passed. The fourth episode corresponds to the package of law changes of the then finance minister Lalovac in January 2015 (law and rulebook changes related to VAT, income tax, lottery taxation, real estate transfer tax and consumption tax).

Besides the stated five media-based uncertainty indicators, we also analyse four measures of disagreement. The first one is calculated from the proportions of responses to BCS question 4 (European Commission, 2014):

How do you expect the general economic situation in this country to develop over the next 12 months? It will: a) get a lot better, b) get a little better, c) stay the same, d) get a little worse, e) get a lot worse, and f) don't know. 
Based on the methodology of Bachmann, Elstner and Sims (2013), a disagreement indicator (dis_4) is calculated as a standard deviation of (positive and negative) response shares of question 4 :

$$
\operatorname{dis}_{-} 4_{t}=\sqrt{\mathrm{frac}_{t}^{+}+\mathrm{frac}_{t}^{-}-\left(\mathrm{frac}_{t}^{+}-\mathrm{frac}_{t}^{-}\right)^{2}},
$$

where rac $_{t}^{+}$is the share of positive answers $(a+b)$, and rac $_{t}^{-}$is the share of negative answers $(d+e) .{ }^{5}$ In the next step, dis_4 is standardized, and finally scaled to have an expected value of 100 and a standard deviation of 10 (for easier interpretation).

Following the exact same methodology, we also calculate the disagreement stemming from questions on future unemployment rate (Q7, indicator dis_7) and the assessments of appropriate time for major purchases (Q8, indicator dis_8).

In line with the methodology of Girardi and Reuter (2016), we additionally consider a combination of all forward-looking questions from the BCS. That is a total of 18 questions (17 questions just as in the online appendix of Girardi and Reuter $(2016)^{6}$, plus question 11 from the Consumer Survey, focusing on the likelihood of saving any money in the household). ${ }^{7}$ In calculating this aggregate disagreement measure (dis_agr), all 18 individual standard deviations of responses (relation 1) are standardized, then averaged and finally scaled for easier interpretation. That way, an aggregate indicator of forecasting disagreement is obtained, covering five different business sectors: manufacturing industry, construction, services, retail trade and the consumer sector. The results of all analysed disagreement measures are presented in graph 6. Respecting the fact that dis_agr is available only from May 2008, very similar tendencies are noticed in dis_4, dis_7, and dis_agr. The disagreement of economic agents is the highest during the crisis onset, followed by a continuous and long-term decline. On the other hand, dis_8 exhibits a somewhat longer-lasting growth after the outbreak of the crisis. This shows that the consumers did not considerably revise their uncertainty assessments as related to major purchases, even until the end of 2016.

That way we obtain a total of 10 individual uncertainty indicators. Besides them, we also utilize the following macroeconomic variables in VAR modelling: 3-month money market interest rate (int), real average wage index (rwage), HICP index $(H I C P)$, and the industrial production index $($ ind $) .{ }^{8}$ Considering the fact that Croatia is a small open economy, we also utilize the following control variables: STOXX 600 stock index (STOXX600), oil prices (oil), euro area industrial

\footnotetext{
${ }^{5}$ Answers "don't know" are excluded from further consideration.

${ }^{6}$ Girardi and Reuter (2016) obtain rather standard results in comparison to the related literature. All the observed disagreement measures have a negative and strictly short-run effect on the euro area GDP.

${ }^{7}$ For the exact wording of all BCS questions, see European Commission (2014).

${ }^{8}$ The industrial production index is analysed as a proxy for GDP to increase the data frequency and ensure an adequate sample size. The same procedure is also used in similar studies: Bloom (2009), Bachmann, Elstner and Sims (2013), Jurado, Ludvigson and Ng (2015), and Baker, Bloom and Davis (2016).
} 
production $\left(i n d^{*}\right)$, and the 3-month euro area money market interest rate (int*). All analysed variables are seasonally adjusted using the ARIMA X12 method. A description of individual variables, together with data sources and the available data spans, are given in appendix 2.

\section{GraPh 6}

\section{Disagreement measures}

a) dis_4

b) dis_ 7
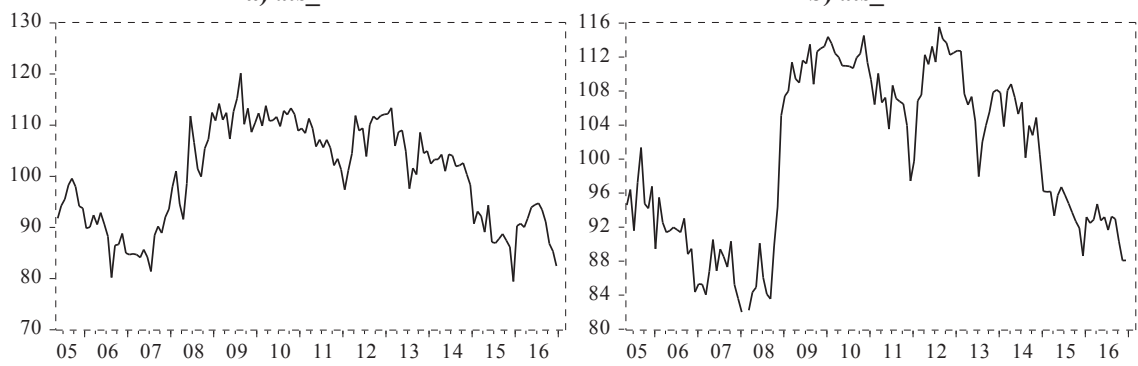

c) dis_8

d) dis_agr
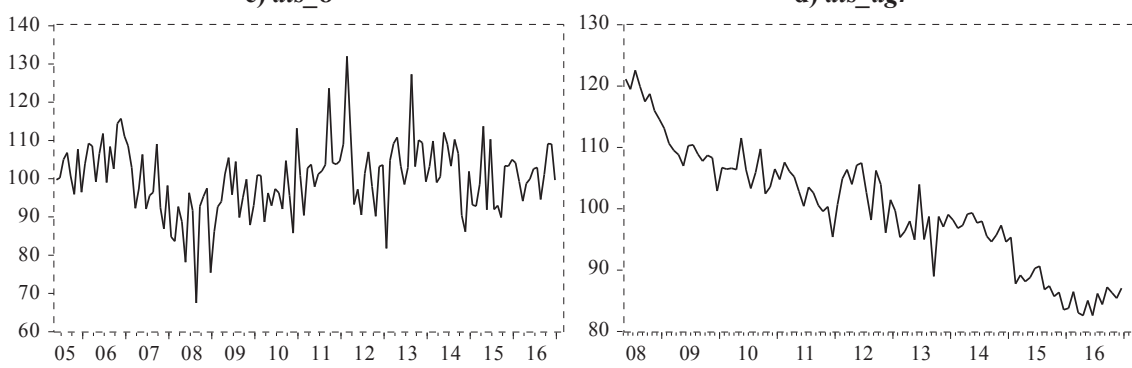

Source: Authors' calculations.

\subsection{METHODOLOGICAL GROUNDS}

The influence of economic uncertainty on the Croatian economy will be tested using two classes of econometric models. The first step entails a customary VAR model with time-fixed parameters, while the second step includes a more complex VAR model with time-varying parameters (Primiceri, 2015; and del Negro and Primiceri, 2015).

In the literature it is common to analyse the interrelationship between uncertainty and economic activity using VAR models (Bloom, 2009; Bachmann, Elstner and Sims, 2013; Jurado, Ludvigson and Ng, 2015; Girardi and Reuter, 2016). The same methodological principle is also the foundation of this paper. Its starting point is the estimation of a structural VAR model in the vein of Blanchard and Quah (1989), while the analysed dataset and their ordering in the innovation analysis is mostly taken from the above studies. Therefore, the starting VAR model comprises the following variables (in the exact order): unc (uncertainty indicator), int, rwage, HICP, and ind. Complying with the mentioned papers (Bloom, 2009; Bachmann, Elstner and Sims, 2013; Jurado, Ludvigson and Ng, 2015; Girardi and Reuter, 2016), all variables except int and $u n c$ are in logs. 
We estimated ten different versions of the initial VAR model. In each of them unc is represented by a different uncertainty indicator: five media-based, four disagreement measures, and finally a composite uncertainty indicator (score), obtained by principal component analysis from the five media-based measures. ${ }^{9}$ Its basic principle is that each uncertainty type (the media, recession, tax changes, politics, and natural disasters) affects economic activity in some (not necessarily the same) way. Here we present an effort to aggregate the stated sorts of uncertainty to a macro level, and analyse its impact on the economic activity.

The next step of the analysis is to estimate the following structural VAR model:

$$
\sum_{i=0}^{p} \mathrm{~A}_{i} \mathrm{Y}_{t}=\varepsilon_{t}
$$

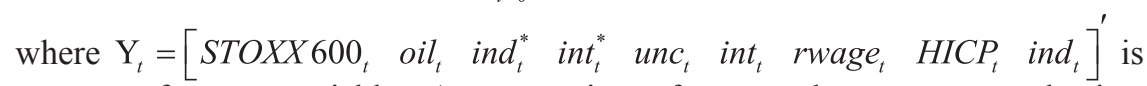
a vector of system variables, $A_{i}$ are matrices of structural parameters, and $\varepsilon_{t}$ is a vector of i.i.d. normally distributed (structural) error terms. ${ }^{10}$

Since previous studies of economic uncertainty (Bloom, 2009; Bachmann, Elstner and Sims, 2013; Jurado, Ludvigson and Ng, 2015; Girardi and Reuter, 2016) deal with developed western economies like the USA, the euro zone or Germany, it comes as no surprise that their VAR models are restricted solely to a set of domestic variables. Considering the fact that Croatia is a small open economy, we augment the initial VAR model by three separate foreign variables: STOXX600, oil, ind*, and int*. Taking these into account, the vector of system variables can be disaggregated into two distinct blocks:

$$
\mathrm{Y}_{t}=\left[\mathrm{Y}_{1, t}, \mathrm{Y}_{2, t}\right]^{\prime}
$$

where $\mathrm{Y}_{1, t}$ is the foreign, and $\mathrm{Y}_{2, t}$ is the domestic block of variables. To be specific, the stated blocks are given as $\mathrm{Y}_{1, t}=\left[\begin{array}{llll}S T O X X 600_{t} & \text { oil } & \text { ind } \\ t & \text { int }\end{array}\right]^{*}$ and $\mathrm{Y}_{2, t}=\left[\begin{array}{lllll}\text { unc } & \text { int } & \text { rwage }_{t} & \text {HICP}_{t} & \text { ind }_{t}\end{array}\right]^{\prime}$.

Further on, the matrices of structural parameters $\mathrm{A}_{i}$ (quantifying the interrelationships among the system variables up to period $p$ ) can be presented as follows:

$$
\mathrm{A}_{i}=\left[\begin{array}{cc}
A_{11}^{i} & A_{12}^{i} \\
A_{21}^{i} & A_{22}^{i}
\end{array}\right], \mathrm{i}=0, \ldots, p
$$

\footnotetext{
${ }^{9}$ score is obtained as the first principal component of the five analysed variables (the obtained eigenvalues is equal to 2.1645). The corresponding weights (loadings) are: 0.61 for $B B D, 0.22$ for nature, 0.32 for PI6, 0.28 for polit and 0.63 for $R_{-}$index. It can therefore be concluded that the lion's share of aggregate uncertainty can be attributed to media reports $(B B D)$ and recession $\left(R_{-}\right.$index $)$. They are followed by tax changes and political instability, while the natural disasters have the weakest influence. The proportion of the total variance explained by the first component is 0.4329 . It should be noted that Baker, Bloom and Davis (2016) apply a similar strategy of aggregating different types of uncertainty, but they apply arbitrarily chosen weights.

${ }^{10}$ It is important to notice that the constant term is not included in equation (2) for simplicity. However, it has been included in the empirical estimation of the model in this paper.
} 
The assumption that external shocks influence the domestic economy (and not vice versa) effectuates in the block exogeneity restriction $\mathrm{A}_{12}^{i}=0$.

Let $\mathrm{A}_{0}$ be the matrix of parameters quantifying contemporaneous interrelationships among system variables. Then, the reduced-form VAR model can be obtained by multiplying equation (2) by matrix $\mathrm{A}_{0}^{-1}$ :

$$
\mathrm{Y}_{t}=\sum_{i=1}^{p} \mathrm{~B}_{i} \mathrm{Y}_{t-i}+\mathrm{u}_{t}
$$

where $\mathrm{B}_{1}, \mathrm{~B}_{2}, \ldots, \mathrm{B}_{\mathrm{p}}$ are parameter matrices of the reduced-form VAR model, and $\mathrm{u}_{t}$ is a vector of i.i.d. error terms. Lütkepohl (2005) shows that matrices $\mathrm{B}_{i}$ keep the block exogeneity restriction:

$$
\mathrm{B}_{i}=\left[\begin{array}{cc}
B_{11}^{i} & 0 \\
B_{21}^{i} & B_{22}^{i}
\end{array}\right], i=1, \ldots, p
$$

To identify the structural shocks $\varepsilon_{t}=\mathrm{A}_{0} \mathrm{u}_{t}$, it is necessary to introduce additional restrictions.

Considering the fact that in all $9 \cdot 8 / 2=36$ restrictions are needed for the analysed system of 9 variables, Cholesky decomposition is employed. Since $\mathrm{A}_{0}$ is a lower triangular matrix, this enables the exact identification of the system. The variable ordering in Cholesky decomposition is given as follows: STOXX600 $_{t}$ oil $_{t}$ ind $_{t}^{*}$ int $_{t}^{*}$ unc $c_{t}$ int rwage $_{t}$ HICP $_{t}$ ind $_{t}$.

The set of analysed variables is mostly taken from similar international studies (Bloom, 2009; Bachmann, Elstner and Sims, 2013; Jurado, Ludvigson and Ng, 2015; Girardi and Reuter, 2016). It should be noted that two of the thereby examined variables (working hours and employment level) that are utilized by Jurado, Ludvigson and Ng (2015), and Girardi and Reuter (2016) are not recorded in Croatia at all, or the series at hand is too short.

As the last relevant remark regarding the structural VAR model, it should be noted that all analysed variables are examined in levels; despite the fact the ADF test results indicate nonstationarity. ${ }^{11}$ The first reason is that structural VAR models tolerate nonstationarity (Lütkepohl and Krätzig, 2004), and the other one is that the exact same procedure was also followed by the authors of similar studies (Bloom, 2009; Bachmann, Elstner and Sims, 2013; Jurado, Ludvigson and Ng, 2015; Girardi and Reuter, 2016).

In the next step of the analysis, we estimate a structural VAR model with timevarying parameters and a time-varying covariance matrix of residuals (Primiceri, 2005; del Negro and Primiceri, 2015). The main motivation for the utilization of this model is the questioning of the hypothesis that uncertainty has a different

\footnotetext{
${ }^{11}$ The results are available upon request.
} 
effect on economic activity in different phases of the economic/political cycles. We start from the following reduced-form VAR model:

$$
\mathrm{Y}_{t}=\mathrm{b}_{t}+\mathrm{B}_{1, t} \mathrm{Y}_{t-1}+\ldots+\mathrm{B}_{k, t} \mathrm{Y}_{t-k}+\mathrm{u}_{t}
$$

where $\mathrm{Y}_{t}$ is a $n \times 1$ vector of endogenous variables, $\mathrm{b}_{t}$ is a vector of time-varying intercepts, $\mathrm{B}_{i, t}(i=1, \ldots, k)$ are the $n \times n$ matrices of time-varying parameters, and $\mathrm{u}_{t}$ is a $n \times 1$ vector of heteroscedastic shocks with a time-varying covariance matrix $\Omega_{t}$. The stated model can be reformulated into a structural VAR specification of the following form:

$$
\begin{aligned}
& \mathrm{Y}_{t}^{\prime}=\mathrm{X}_{\mathrm{t}}^{\prime} \mathrm{B}_{t}+\mathrm{A}_{t}^{-1} \Sigma_{t} \varepsilon_{t}, \\
& \mathrm{X}_{t}^{\prime}=\mathrm{I}_{n} \otimes\left[1, \mathrm{Y}_{\mathrm{t}-1}^{\prime}, \ldots, \mathrm{Y}_{\mathrm{t}-\mathrm{k}}^{\prime}\right],
\end{aligned}
$$

where $\mathrm{A}_{t}$ is a lower-triangular matrix of the following form:

$$
\mathrm{A}_{t}=\left[\begin{array}{cccc}
1 & 0 & \ldots & 0 \\
\alpha_{21, t} & 1 & \ddots & \vdots \\
\vdots & \ddots & \ddots & 0 \\
\alpha_{n 1, t} & \ldots & \alpha_{n n-1, t} & 1
\end{array}\right]
$$

It is essential to notice that matrix $\mathrm{A}_{t}$ is time-varying, implying that a shock in a certain variable has a time-varying effect on all other variables in the system. Primiceri (2005:823) emphasizes that this kind of specification has two key advantages in comparison to structural break models. The first one is that a model including forward-looking variables (like uncertainty in this paper) favours continuous and smooth changes of model parameters. Additionally, any kind of a learning process adopted by the consumers, firms or policymakers implies continuous (not discrete) parameter shifts.

Further on, $\Sigma_{t}$ is a diagonal matrix of the following type:

$$
\Sigma_{t}=\left[\begin{array}{cccc}
\sigma_{1, t} & 0 & \ldots & 0 \\
0 & \sigma_{2, t} & \ddots & \vdots \\
\vdots & \ddots & \ddots & 0 \\
0 & \ldots & 0 & \sigma_{n, t}
\end{array}\right]
$$

Time-variability of standard deviations of shocks in $\Sigma_{t}$ implies multivariate stochastic volatility, included in the model to account for potentially heteroskedastic shocks and potential nonlinearities in the variable relationships (Primiceri, 2005:823).

Time-varying parameters from matrices $\mathrm{A}_{t}$ and $\mathrm{B}_{t}$ are modelled as random walk processes, and the standard deviations $\sigma_{t}$ are modelled as a geometric random walk process.

$$
\begin{aligned}
& B_{t}=B_{t-1}+v_{t} \\
& \alpha_{t}=\alpha_{t-1}+\zeta_{t}
\end{aligned}
$$




$$
\log \sigma_{t}=\log \sigma_{t-1}+\eta_{t}
$$

It is also assumed that all error terms $\left(\varepsilon_{t}, v_{t}, \zeta_{t}\right.$ and $\left.\eta_{t}\right)$ are jointly normally distributed, and their covariance matrix has the following form:

$$
\mathrm{V}=\operatorname{Var}\left(\left[\begin{array}{c}
\varepsilon_{\mathrm{t}} \\
v_{\mathrm{t}} \\
\zeta_{\mathrm{t}} \\
\eta_{\mathrm{t}}
\end{array}\right]\right)=\left[\begin{array}{cccc}
\mathrm{I}_{\mathrm{n}} & 0 & 0 & 0 \\
0 & \mathrm{Q} & 0 & 0 \\
0 & 0 & \mathrm{~S} & 0 \\
0 & 0 & 0 & \mathrm{~W}
\end{array}\right],
$$

where $\mathrm{I}_{\mathrm{n}}$ is a $n$-dimensional identity matrix, while $\mathrm{Q}, \mathrm{S}$ and $\mathrm{W}$ are positive definite matrices. $\mathrm{S}$ is a block-diagonal matrix, with blocks corresponding to the rows of matrix $\mathrm{A}_{t}$.

Having in mind that the system of equations (8-12) has an extremely large number of parameters, a Bayesian approach would considerably facilitate its estimation. In accordance with the pioneer of this sort of a time-varying VAR model (Primiceri, 2005), we also estimate equation (8) by OLS on the starting 40 observations (2002 M11 - 2006 M02) to calibrate the prior distributions of system parameters. The estimates of parameters from $\hat{\mathrm{B}}_{\mathrm{OLS}}$ are obtained by estimating individual equations of the VAR model, while estimates of $\hat{\mathrm{A}}_{\mathrm{OLS}}$ and $\hat{\sigma}_{\text {OLS }}$ are obtained through a Cholesky factorization of the covariance matrix $\Omega_{t}$ of residuals from the reduced VAR system $\left(\Omega_{t}=\mathrm{A}_{t}^{-1} \Sigma_{\mathrm{t}} \Sigma_{t}^{\prime}\left(\mathrm{A}_{t}^{\prime}\right)^{-1}\right)$. Covariance matrices $\mathrm{V}\left(\hat{\mathrm{B}}_{\mathrm{OLS}}\right)$ and $\mathrm{V}\left(\hat{\mathrm{A}}_{\mathrm{OLS}}\right)$ are also obtained by the standard OLS method. Further on, in accordance with Primiceri (2005), and Cogley and Sargent (2005), the prior distribution of timevarying parameters is taken to be normal, while the prior distribution of hyperparameters from matrices $\mathrm{Q}, \mathrm{W}$, and those from the diagonal blocks of matrix $\mathrm{S}\left(\mathrm{S}_{1}\right.$ and $\left.\mathrm{S}_{2}\right)$, is the inverse Wishart (IW) distribution. Relations (13-19) give the formalization of prior distributions of the utilized Bayesian approach.

$$
\begin{gathered}
\mathrm{B}_{0} \sim N\left(\hat{\mathrm{B}}_{\mathrm{OLS}}, 4 \cdot \mathrm{V}\left(\hat{\mathrm{B}}_{\mathrm{OLS}}\right)\right), \\
\mathrm{A}_{0} \sim N\left(\hat{\mathrm{A}}_{\mathrm{OLS}}, 4 \cdot \mathrm{V}\left(\hat{\mathrm{A}}_{\mathrm{OLS}}\right)\right), \\
\log \sigma_{0} \sim N\left(\log \hat{\sigma}_{\mathrm{OLS}}, \mathrm{I}_{\mathrm{n}}\right), \\
\mathrm{Q} \sim I W\left(k_{Q}^{2} \cdot 40 \cdot \mathrm{V}\left(\hat{\mathrm{\beta}}_{\mathrm{OLS}}\right), 40\right), \\
\mathrm{W} \sim I W\left(k_{W}^{2} \cdot 4 \cdot \mathrm{I}_{\mathrm{n}}, 4\right), \\
\mathrm{S}_{1} \sim I W\left(k_{S}^{2} \cdot 2 \cdot V\left(\hat{\mathrm{A}}_{1, \mathrm{OLS}}\right), 2\right), \\
\mathrm{S}_{2} \sim I W\left(k_{S}^{2} \cdot 3 \cdot V\left(\hat{\mathrm{A}}_{2, \mathrm{OLS}}\right), 3\right),
\end{gathered}
$$

where the covariance matrix from equations (13-14) is up to a scalar equal to the covariance matrix obtained by the OLS method. Similarly, the scaling matrix (first 
parameter of the inverse Wishart distribution) for relations $(16,18,19)$ is also up to a scalar equal to the covariance matrix obtained by OLS. The parameter values $k_{Q}=k_{W}=0.01$, and $k_{S}=0.1$ are taken from Primiceri (2005). The degrees of freedom of $I W$ distributions (equations 16-19) are equal to 40, 4, 2 and 3 (respectively).

Starting from the stated prior distributions, del Negro and Primiceri (2015) introduce a Markov Chain Monte Carlo (MCMC) algorithm for estimating the posterior distributions of the model parameters $\left(\mathrm{B}^{T}, \mathrm{~A}^{T}, \Sigma^{T}\right.$ and the hyperparameters from matrix V). To be concrete, we apply a specific form of the Gibbs sampler (named "algorithm 3" by del Negro and Primiceri, 2015:1343) on the remaining part of data after the initial 40 observations (2006 M03 - 2016 M12). The empirical results (shown in section 4) are obtained through 10000 MCMC draws from the posterior distributions of the model parameters.

\section{EMPIRICAL RESULTS}

Prior to concrete econometric analysis of the observed time series, we first present their correlation matrix (table 1).

The issue of special interest here is the correlation between all the suggested uncertainty measures, as well as the correlation between each individual uncertainty indicator and economic activity. A glance at the last row of table 1 reveals that six out of ten suggested indicators are negatively (and mostly significantly) correlated to the domestic industrial production, as well as to real wages and CROBEX. These inferences are almost entirely in line with the stylized fact of uncertainty being a countercyclical variable (Bloom, 2014). There are only two uncertainty measures that deviate from this conclusion (dis_4 and dis_agr). These two variables are because of that not shown in table 1 to save space, and are not examined in further econometric analysis. ${ }^{12}$

In the following steps, two (time-fixed) structural VAR models are estimated: the initial, reduced-form one (including only domestic variables) and the augmented one (comprising also the foreign variables). Each of the two models is estimated in eight different specifications, i.e. each of them includes a different uncertainty indicator. ${ }^{13}$ The lag order in each model is chosen by the Schwarz information criterion. ${ }^{14}$ In their final versions, all eight models are estimated with three lags. The forecasting error variance decomposition of ind in the augmented model (for the forecasting horizon of 24 months) is presented in table 2.

\footnotetext{
${ }^{12}$ We also tried to quantify uncertainty through a GARCH estimation of conditional variance of the industrial production index (in line with e.g. Fountas et al., 2006), but that variable was negligibly positively correlated to economic activity. The same conclusion is also drawn for Google trends data (frequency of Web searches by the terms "economic crisis" and "recession") for Croatia. Therefore, all of these alternatives are, just as dis_4 and dis_agr, excluded from further analysis.

${ }^{13}$ The results of the initial and augmented model (impulse response functions and forecasting error variance decompositions) are qualitatively very similar. To save space, only the augmented model results are shown here. ${ }^{14}$ In cases when the chosen lag order was not sufficient to eliminate autocorrelation from the model, additional lags were successively added to the model up to the non-rejection of the null hypothesis of a Lagrange Multiplier autocorrelation test of $12^{\text {th }}$ order.
} 
462

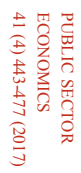

$\Xi$

8

范

₹

:

䒹

:

\%)

妾|

की

ถั้ $\mid$ | $\mid$ |

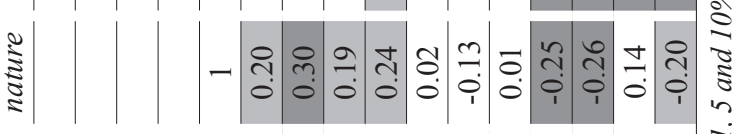

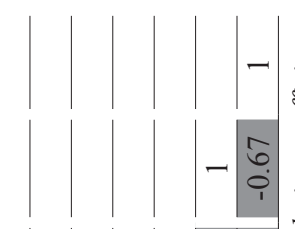

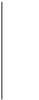
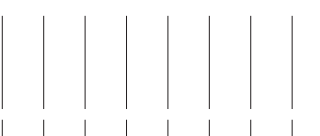

$\sqrt{2}$
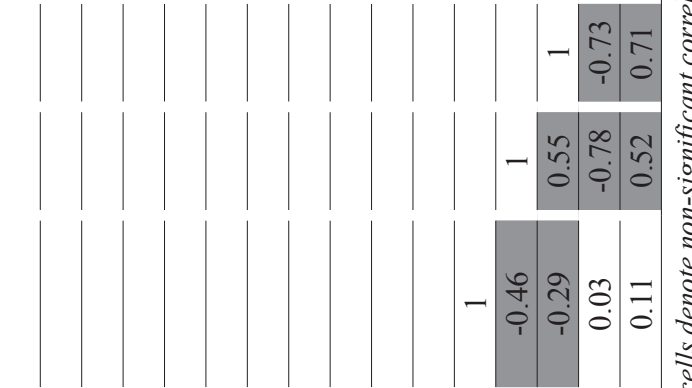

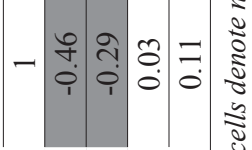

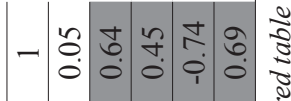

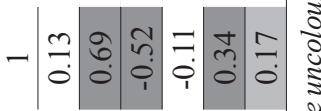

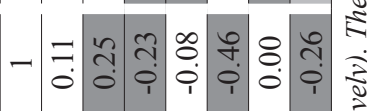

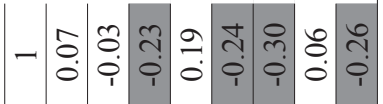

-

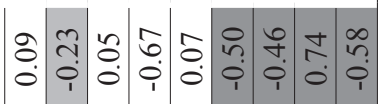

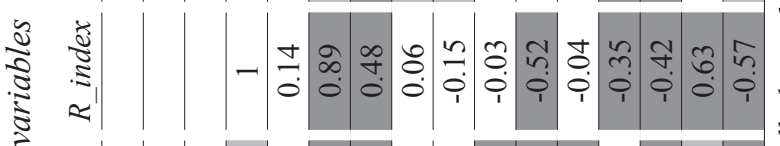

๘

₹

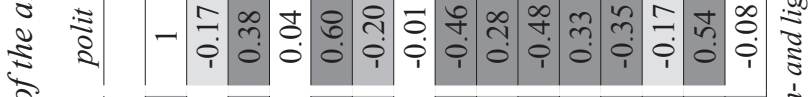

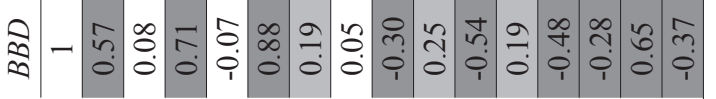

I

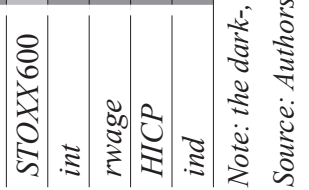


TABLE 2

Forecasting error variance decomposition (augmented model)

\begin{tabular}{|c|c|c|c|c|c|c|c|c|c|}
\hline $\begin{array}{l}\text { Uncertainty } \\
\text { indicator } \\
\text { unc }\end{array}$ & STOXX 600 & oil & ind $^{*}$ & int $^{*}$ & unc & int & rwage & HICP & ind \\
\hline$B B D$ & 0.25 & 0.16 & 0.06 & 0.04 & 0.01 & 0.01 & 0.09 & 0.02 & 0.36 \\
\hline polit & 0.24 & 0.13 & 0.06 & 0.04 & 0.04 & 0.01 & 0.08 & 0.02 & 0.37 \\
\hline PI6 & 0.26 & 0.16 & 0.05 & 0.01 & 0.01 & 0.01 & 0.09 & 0.03 & 0.34 \\
\hline$R \_$index & 0.23 & 0.15 & 0.06 & 0.04 & 0.04 & 0.01 & 0.09 & 0.02 & 0.34 \\
\hline nature & 0.25 & 0.15 & 0.06 & 0.05 & 0.01 & 0.01 & 0.09 & 0.02 & 0.36 \\
\hline score & 0.25 & 0.16 & 0.06 & 0.04 & 0.01 & 0.01 & 0.09 & 0.02 & 0.36 \\
\hline dis_7 & 0.12 & 0.21 & 0.12 & 0.10 & 0.00 & 0.01 & 0.08 & 0.03 & 0.33 \\
\hline dis_8 & 0.13 & 0.19 & 0.11 & 0.09 & 0.03 & 0.01 & 0.08 & 0.02 & 0.34 \\
\hline
\end{tabular}

Source: Authors'calculations.

It is shown that the lion's share of the variability of Croatian economic activity can individually be attributed (except the ind variable itself) to the STOXX 600 index and oil prices on the world market. This inference is in line with the results of Krznar and Kunovac (2010), which show that foreign variables explain approximately $50 \%$ of Croatian GDP variability. Further on, it is interesting that STOXX600 maintains a considerably high variance share in all eight augmented models. This can also, in a wider sense, be linked to the overall importance of the financial sector for the Croatian economic activity (Dumičić and Krznar, 2013). Additionally, it seems that it is reasonable to postulate that energy prices are the main determinant of economic activity (Croatian National Bank, 2015).

Finally, we show that uncertainty does not explain a particularly large proportion of industrial production variability. $R$ _index and polit are shown to be the "relative winners" with the share of $4 \%$, while the other indicators have smaller or even trivial effects on economic activity. Besides the forecasting error variance decomposition, it is also important to examine the impulse response functions (IRFs) to gain an insight into the dynamic interdependence of the analysed variables. Graph 7 gives the estimated IRFs of industrial production in response to a shock in uncertainty. ${ }^{15}$

Depicting the $68 \%$ confidence interval on graph 6 (in line with similar studies: Bloom, 2009; Primiceri, 2005; del Negro and Primiceri, 2015; Jurado, Ludvigson and Ng, 2015; Belongia and Ireland, 2016) enables indirect conclusions about the statistical significance of IRFs (depending on the confidence interval including zero or not). Most IRFs from graph 7 are rather similar (with the exception of polit) and reveal a significant short-run uncertainty effect. Nevertheless, the duration of the effect is extremely short, and it fades away after only a few months. The impact of political uncertainty appears to be relevant only in the medium-term. Economic activity does not seem to respond to political turmoil in the short run.

\footnotetext{
${ }^{15}$ We suppress the IRFs resulting from shocks in variables $B B D$ and nature, since these were not shown to be significantly different from zero. They are available upon request.
} 


\section{GraPH 7}

Industrial production IRFs (shock in economic uncertainty)

a) $B B D$
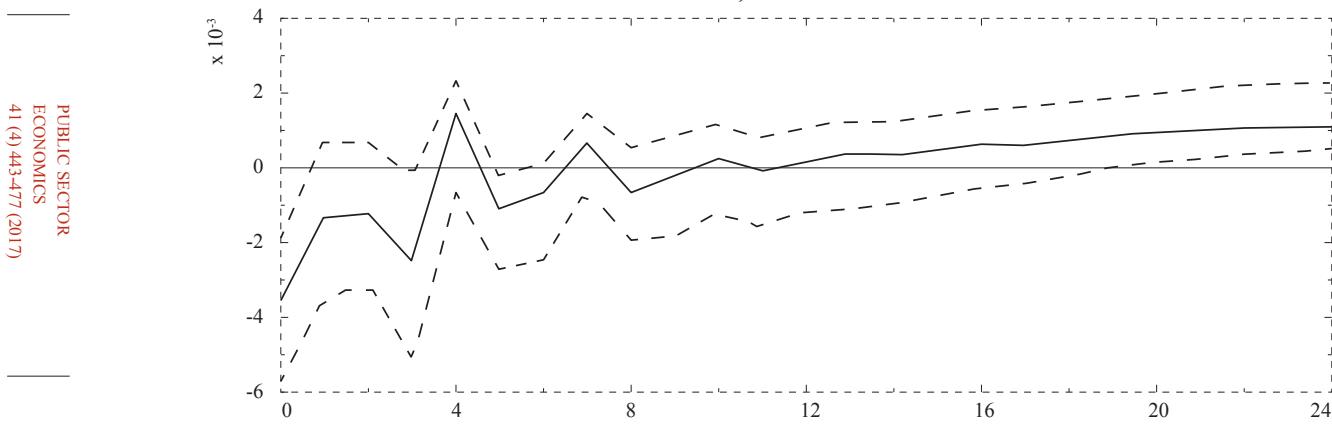

b) polit

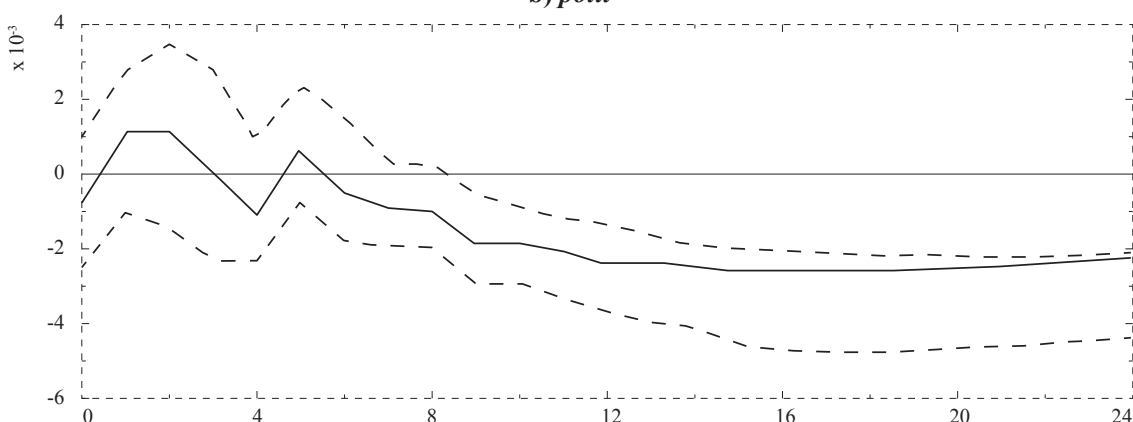

c) PI6

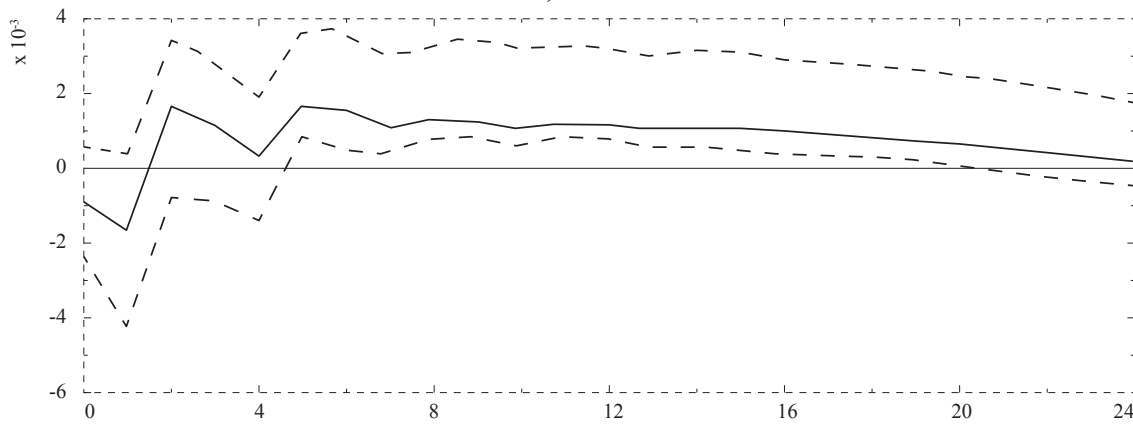

d) $R_{-}$index

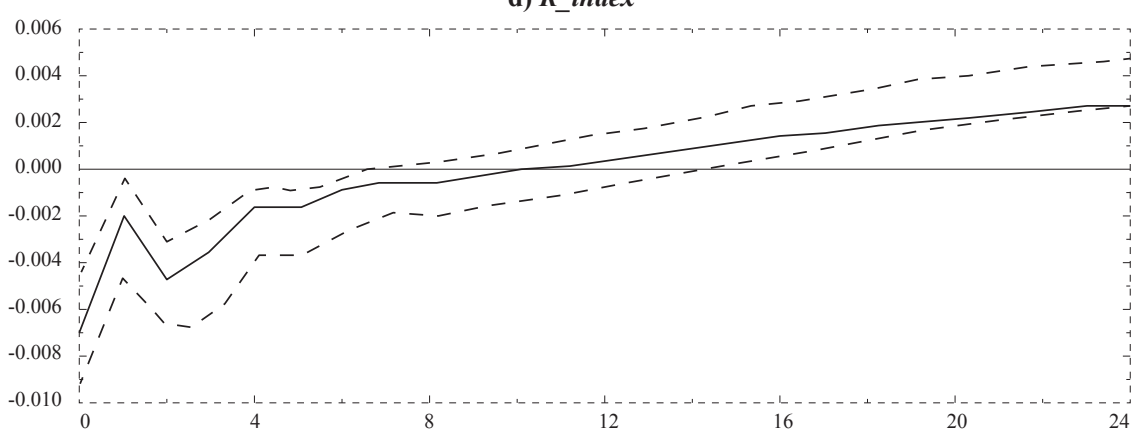


e) score

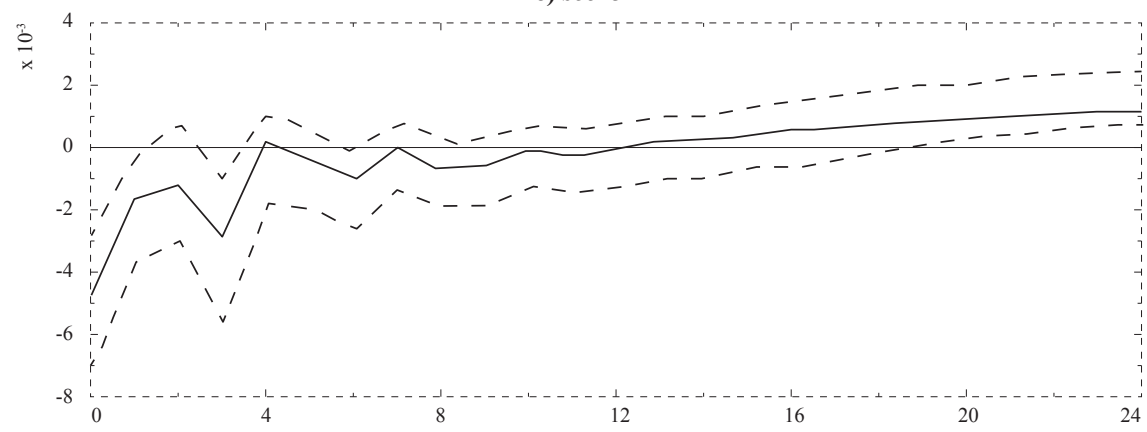

f) dis_ 8

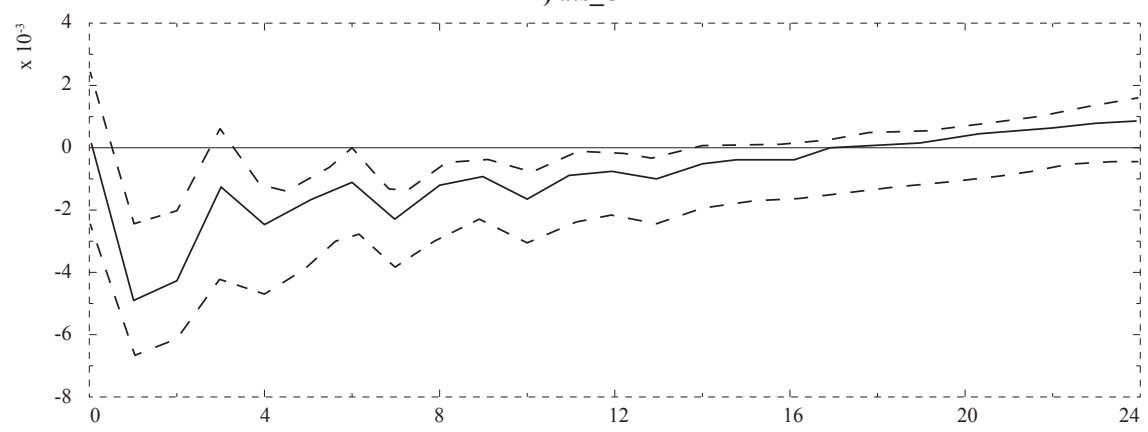

Note: Time on the $x$-axis is measured in months.

Source: Authors'calculations.

The estimated IRFs are of rather similar intensity. A one standard deviation shock in the variables $B B D, P I 6, R$ index, score, and dis 8 has the strongest effect in the initial period or in the first month after the shock. The stated influence corresponds to a reduction of economic activity by $0.45 \%, 0.3 \%, 0.66 \%, 0.47 \%$, and $0.57 \%$ (respectively). For instance, the standard deviation of residuals from the VAR equation with PI6 as the dependent variable is equal to 1.84 . Considering that ind is in logs, this result implies that each additional change of fiscal legislation in a 6 month period causes a decrease of industrial production by $0.16 \%$ (conditional on all other variables in the system).

It should be noted that Bloom (2009) applies a similar analysis for the USA, detecting an abrupt short-run activity reduction as a response to an uncertainty shock. Such a downturn is followed by a recovery, ending with an overshooting effect. In the case of the analysis presented here, the IRFs are characterized by rather similar effects. As the end of the $24^{\text {th }}$ month horizon comes near, the uncertainty effects even cross over to the positive domain. An obvious exception is again polit, whose negative effect is apparent only in the medium run.

The following empirical step is the estimation of a time-varying VAR model (del Negro and Primiceri, 2015). Having in mind that the analysed model includes a large number of parameters that are numerically challenging to estimate (equa- 
tions 8-12), empirical application of this model regularly include three variables at most (Primiceri, 2005; del Negro and Primiceri, 2015; Belongia and Ireland, 2016). Since it was not possible to examine the widest possible model specification, we estimated several trivariate models. Each of them comprises a single uncertainty indicator and the industrial production index. The third, alternating position is held by one of the variables with the highest ind variance decomposition share in the structural VAR with time-fixed parameters. Variables $S T O X X 600$, $u n c$ and ind (in this exact Cholesky ordering) are considered for the first timevarying parameters VAR. Namely, those are the variables with the highest individual share in the forecasting error variance of ind: $21.63 \%, 1.88 \%$, and $35.00 \%$ (respectively, averaged by rows of table 2 , i.e. by uncertainty indicators), summing up to a respectable $58.5 \% .^{16}$

Graph 8 shows the time-varying IRFs of industrial production to a shock in six analysed uncertainty indicators. The date points for which the IRFs are calculated are conceptually similar to those of Primiceri (2005). Namely, Primiceri performs a comparable VAR analysis for the US business cycle turning points. A similar principle is also applied here, so the targeted date points are: 2008 M06 (peak of the cycle, followed by a drastic fall of economic activity), 2010 M04 (start of the economic recovery programme by the government of Jadranka Kosor), 2014 M12 (end of the recession), and 2016 M09 (the highest value of the industrial production index in the post-crisis period). The identified date points are analysed for the indicators $B B D, P I 6, R$ index, and score. For the nature variable, $2010 \mathrm{M} 04$ is modified to 2014 M05 to account for the Eastern Slavonia floods at that time. For the polit indicator, the time points are determined by the dates of parliamentary elections (2007 M11, 2011 M12, 2015 M11, and 2016 M09), and by the middle points of electoral cycles as representatives of politically "calmer" times (2009 M11 and 2013 M11). ${ }^{17}$ The first conclusion obtained from graph 8 is that most of the analysed uncertainty measures exhibit a time-varying effect on economic activity. This is particularly pronounced for variables $B B D, P I 6, R \_$index, and score, while the influence of political turmoil and natural disasters is relatively constant throughout the entire analysed period. The basic principle of the detected time-variability is that the uncertainty effect is the strongest at the very onset of the crisis (2008 M06), and it gradually fades away with time. It is the weakest in the last analysed time point (2016 M09), when it practically converges to zero. The only exception from the observed pattern is PI6. Fiscal instability has a "less negative" short-run effect at the crisis epicentre, while the intensity of the stated negative influence increases as the economy heats.

\footnotetext{
${ }^{16}$ Alternatively, STOXX 600 was replaced by oil (with the average share in the forecast error variance of industrial production equal to $16.38 \%$ ). The results obtained that way showed to be qualitatively very similar. ${ }^{17}$ For each of the stated indicators, somewhat different date points are considered, but the basic conclusions have remained the same.
} 
GRAPH 8

Comparison of time-varying IRFs of industrial production (shock in economic uncertainty)

a) $B B D$

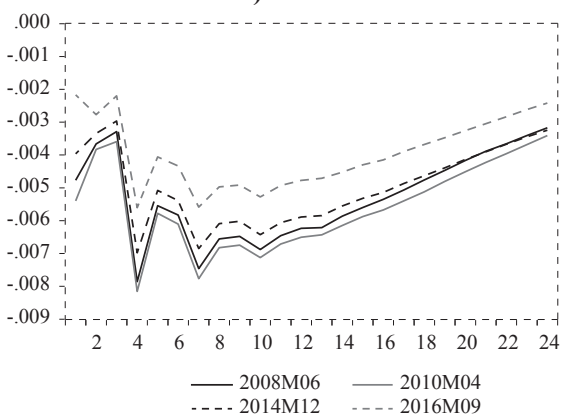

c) PI 6

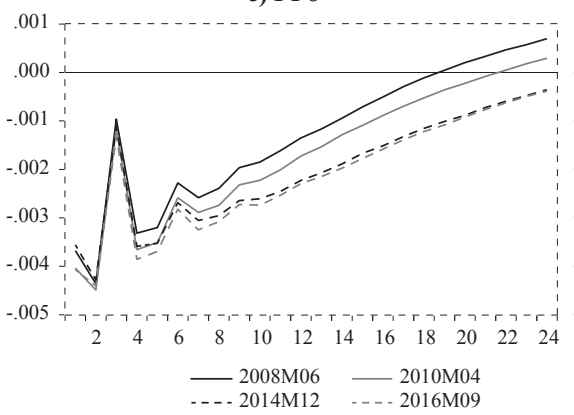

e) nature

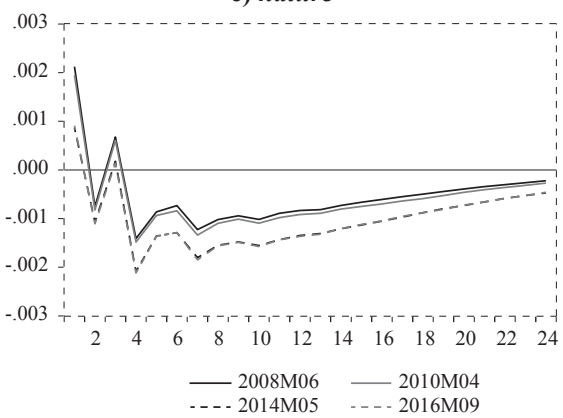

Note: Time on the $x$-axis is measured in months. b) polit

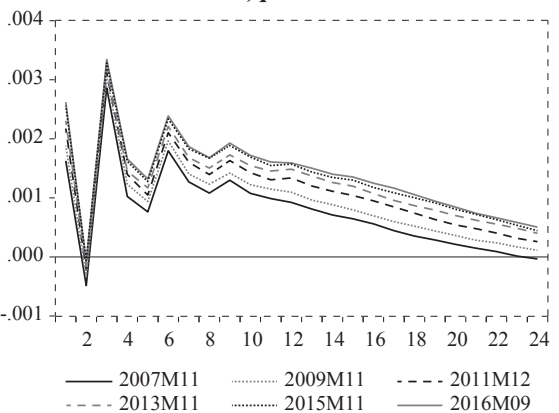

d) $R$ index

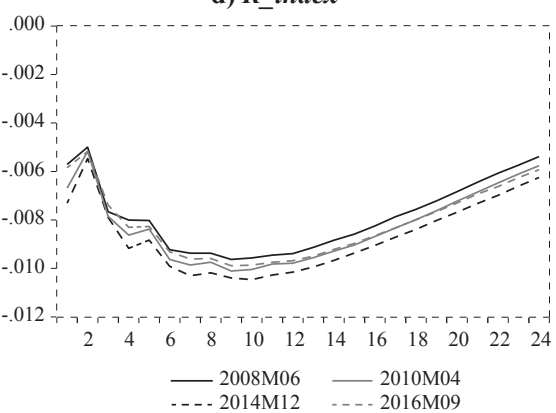

f) score

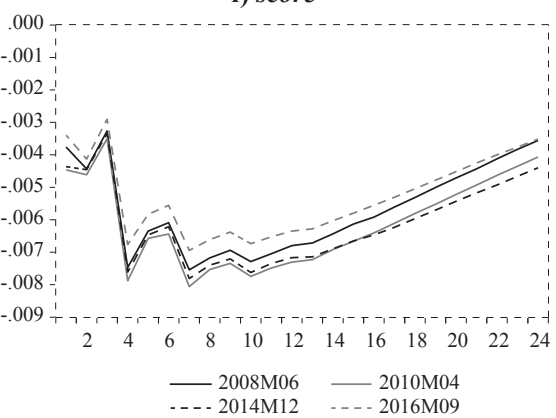

Source: Authors'calculations.

In the context of policymaking, a question arises as to whether the introduction of large and frequent fiscal changes in the system is justifiable. Considering that PI6 has the weakest effect in the crisis, this partially exculpates fiscal expansion as a counter-recession measure. It should be highlighted, of course, that the negative effect of fiscal instability noticed here is of a merely short-run nature.

Graphs 9-11 present very similar information. Except from the sole IRFs (posterior distribution means), they also contain its $16^{\text {th }}$ and $84^{\text {th }}$ percentile. This is in line 
with similar reports (Bloom, 2009; Primiceri, 2005; del Negro and Primiceri, 2015; Jurado, Ludvigson and Ng, 2015; Belongia and Ireland, 2016). That way we obtain the middle $68 \%$ of the posterior distribution, which comes down to the interval of \pm 1 standard error in the normal distribution case. ${ }^{18}$ A short overview of graphs 9-11 reveals that the effects of shocks in all three uncertainty indicators are depicted by J-curves. The function shapes are somewhat different from those in graph 7, and their maximum values (in absolute terms) are somewhat smaller. However, all the main conclusions remain intact: the short-run uncertainty effect is significant, negative, and quickly diminishing. The IRFs estimated at the very start of the crisis are quite persistent, but with the heating of the economy (as 2016 M09 becomes closer), they get closer to zero. ${ }^{19}$

\section{GraPh 9}

Time-varying IRFs of industrial production (shock in $R \_$index)

\section{a) $2008 \mathrm{M06}$}

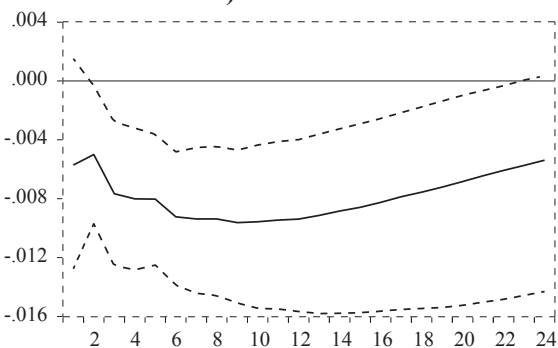

c) $2014 \mathrm{M} 12$

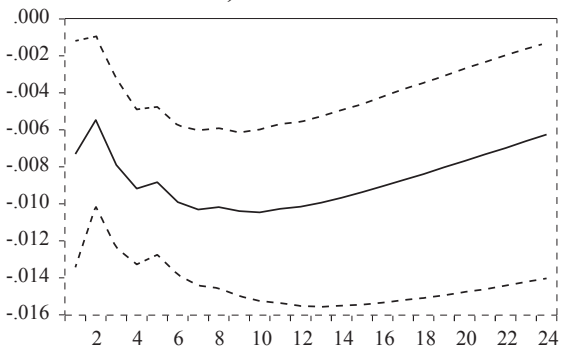

b) $2010 \mathrm{M04}$

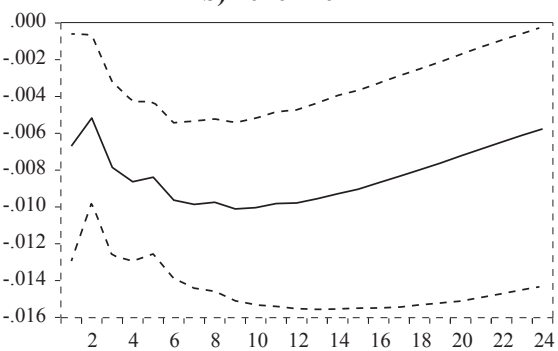

d) $2016 \mathrm{M09}$

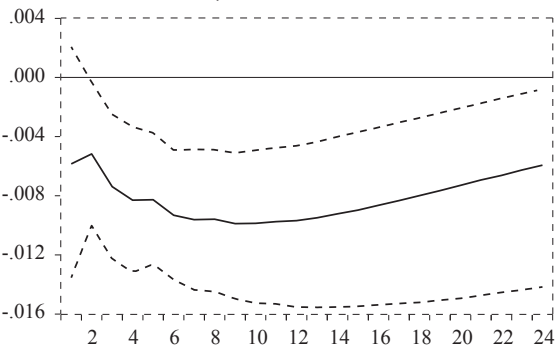

Note: Time on the $x$-axis is measured in months.

Source: Authors' calculations.

\footnotetext{
${ }^{18}$ IRFs for $B B D$, polit, and nature are left out because they were not statistically significant.

${ }^{19}$ As a robustness check, we also attempted to redo the analysis with quarterly data for the Croatian economy (comprising GDP as the dependent variable and quarterly versions of other variables, obtained as averages of the corresponding monthly observations). However, due to there being too few data points and to the complexity of the assumed relationships between the observed variables, the utilized numerical methods used to estimate the model parameters were not able to converge to stable estimates.
} 


\section{Graph 10}

Time-varying IRFs of industrial production (shock in PI6)

a) $2008 \mathrm{M06}$

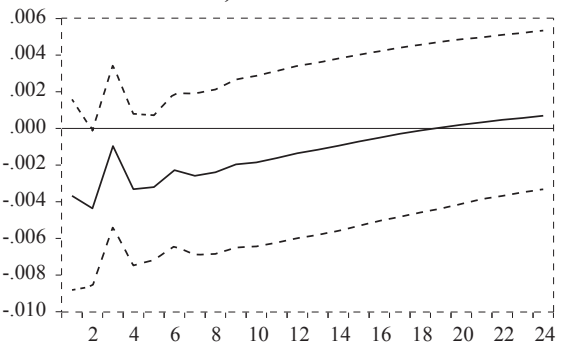

c) $2014 \mathrm{M} 12$

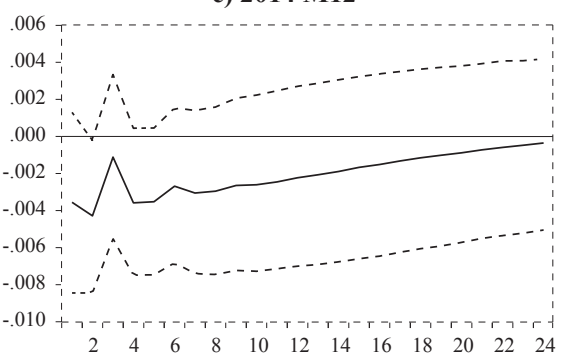

Note: Time on the $x$-axis is measured in months.

\section{b) $2010 \mathrm{M04}$}

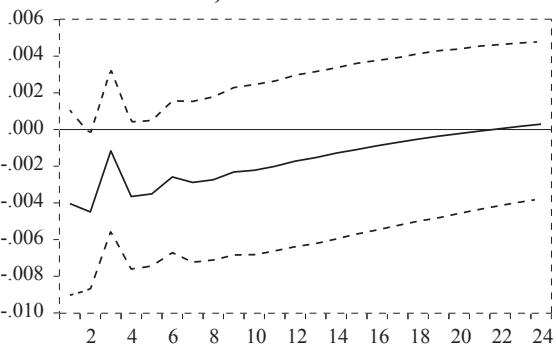

d) 2016 M09

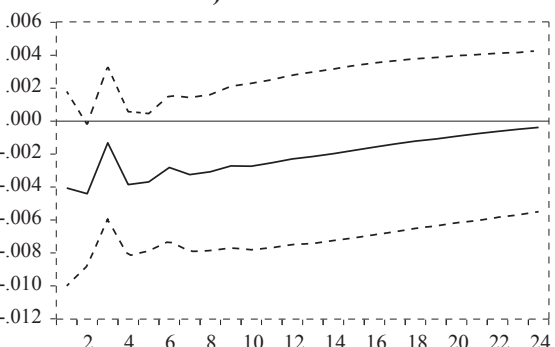

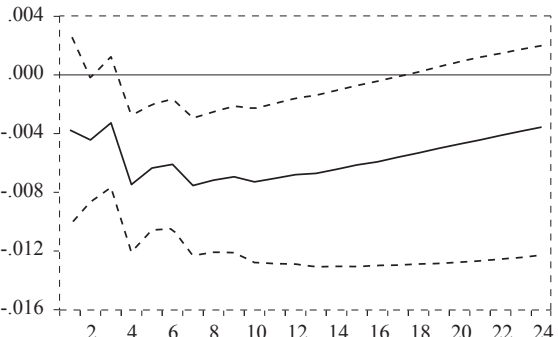

c) $2014 \mathrm{M} 12$

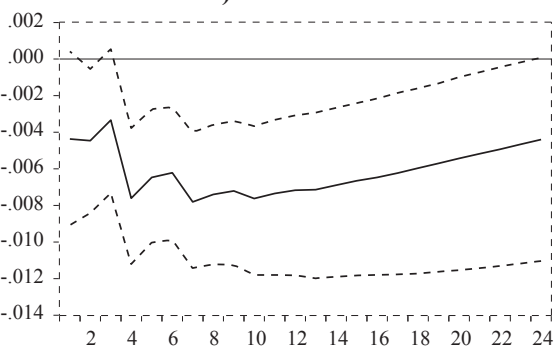

b) $2010 \mathrm{M04}$

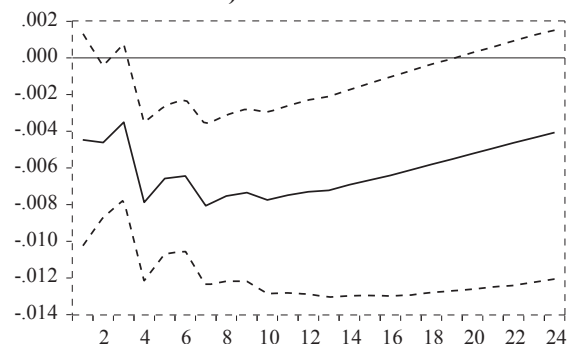

d) $2016 \mathrm{M09}$

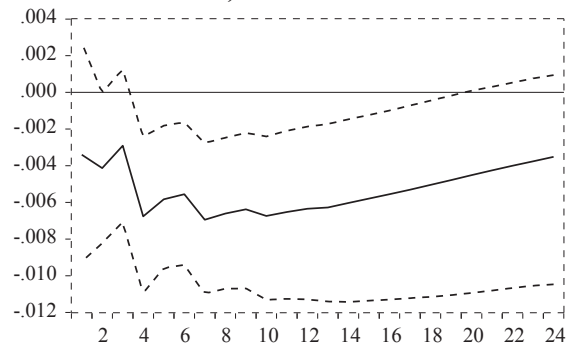

Note: Time on the $x$-axis is measured in months.

Source: Authors'calculations. 


\section{DISCUSSION AND CONCLUSION}

This paper offers an explanation of the intensity and persistence of the recent crisis by introducing the psychological concept of uncertainty in macroeconomic analysis. With that goal, we quantified and analysed eight different uncertainty indicators by utilizing a web database of articles from the most popular Croatian news portals, the Narodne novine repository of legal amendments, and BCS. Out of the considered uncertainty types, the following media based indicators seem to be especially relevant: the R-word index, fiscal legislation uncertainty, and the composite uncertainty indicator obtained by principal component analysis of individual uncertainty measures.

The overall conclusion is, in short, that the uncertainty effect is statistically significant, but short-lived and rather weak. The results of the VAR model with timevarying parameters are especially relevant; confirming that the uncertainty effect (quantified through the R-word index and the composite uncertainty indicator) changes throughout the phases of the business cycle. Its negative influence is the strongest at the very epicentre of the crisis in mid-2008, and it gradually disappears as the economy starts to heat again. These results can be put in relation to the long since observed phenomenon that consumer confidence significantly affects consumption expenditures only upon abrupt and unexpected downturns of economic activity (Garner, 1991). Although confidence (first moment, expected value) is a concept inherently different from uncertainty (second moment, distribution variance), sudden falls of economic activity obviously activate the same mechanisms (wait and see, risk aversion) in economic agents.

The implications of these results for policymakers primarily refer to the importance of adequate crisis communication, but also the general informing of all involved parties about the planned measures of fiscal, monetary, or any other type of economic policy. Recession for sure cannot be avoided by mere timely communication of the economic policy measures to the public (consumers, firms, banks), but the effects of a crisis can probably be held under control to a certain extent. The necessity of sound communication of the planned policy moves was recognized as a conditio sine qua non of efficient economic policy a long time ago (Kramer et al., 2008). On the other hand, recent domestic trends such as the then government's refusal to face the evident crisis in November 2008 (Jutarnji list, 2015) give an example of the negative effect of uncertainty due to inadequate communication.

A special comment should also be devoted to the performance of the fiscal uncertainty indicator, especially with regards to the current implementation of the tax reform in Croatia. To avoid the obviously existing negative short-run effects caused by the large number of fiscal changes, it is vital to present a clear and coherent workflow of tax reform activities in the 4-year period. In addition, without going into any normative issues of equity and wealth distribution, if lowering the tax burden is the proclaimed direction of the tax reform, then all further reform 
activities should keep the same direction (independent of the current economic and political circumstances). That would diminish fiscal instability, which is recognized as a source of confusion and as an obstacle to entrepreneurship and the attraction of FDI even by tax reform working group members (Zrinušić and Vuraić Kudeljan, 2016:31). This premise is also in line with the fourth Bloom (2014:164) condition for the efficiency of the real options channel: uncertainty has a negative effect on the economy (investments, entrepreneurial activities, consumption) only when it is variable (volatile). In situations of permanent uncertainty, economic agents adapt to it. Following the same logic, they will be capable of adjusting their business plans to the coordinated legislation changes in the direction of tax disburdening.

Similar conclusions should also be drawn for the possible future implementation of a macro-reform of revoking various administrative barriers to business (Čučković and Bartlett, 2007) and the cancelling a part of the enormous number of para-fiscal charges that block the development of small and medium entrepreneurship. Impinging on the existing system of business-related legal, administrative, and fiscal regulations would surely generate a certain level of economic uncertainty, but that is by no means a reason to walk-away from reform in the segment of business facilitating. On the contrary, that segment should also be operationalised taking into account the necessity of adequate communication to the interested parties, and by insisting on keeping the long-run course of deregulating business conduction.

This paper presents one of the initial steps needed to elucidate the phenomenon of uncertainty and its influence on macro and micro tendencies. We see a sectoral analysis in the vein of Arčabić (2015) as a potentially fruitful direction for future research, where the savings and borrowing of consumers, companies, and the state would be scrutinized separately. It remains to be seen if the measures of prognostic disagreement (quantified from BCS as the central source of data on psychological concepts in economics) become significant predictors of economic activity, once the number of data points at hand gets larger.

\section{Disclosure statement}

No potential conflict of interest was reported by the authors. 


\section{KEYWORDS USED FOR THE QUANTIFICATION OF MEDIA-BASED UNCERTAINTY INDICATORS}

\section{TABLE A1}

$B B D$

\begin{tabular}{lll} 
Keywords & Logical conjunction I & Logical conjunction II \\
\hline economy & prime minister & uncertainty \\
economic & minister & uncertain \\
& parliament & not certain \\
& Croatian National Bank & risk \\
& CNB & risky \\
& European Central Bank & non-reliable \\
& ECB & not reliable \\
& International Monetary Fund & \\
IMF & \\
& European Commission & \\
& EC & \\
\hline
\end{tabular}

Table A2

$R$ index

Keywords Logical conjunction

economy recession

economic crisis

TABLE A3

polit

\begin{tabular}{ll} 
Keywords & Logical conjunction \\
\hline elections & prime minister \\
electoral & president \\
dismissal & minister \\
dismissed & parliament \\
migrant & Croatian National Bank \\
asylum & CNB \\
Schengen & European Central Bank \\
trial & ECB \\
accusation & International Monetary Fund \\
accused & IMF \\
investigation & European Commission \\
investigated & EC \\
corruption & \\
corruptive & \\
corrupt & \\
affair & \\
prison & \\
custody &
\end{tabular}


TABLe A4

nature

Keywords

Logical conjunction

flood Croatia

hail

drought

earthquake

epidemic

TABLe A5

PI 6

Keywords

Logical negation

tax

dismissal

dismissed

appointment

appointed

municipality

city

county 
TABle A6

Dataset description

Variable

int

\begin{tabular}{ll}
\hline rwage & $\begin{array}{l}\text { interest rate (ZIBOR) } \\
\text { Real net wage; } 2010=100 ; \\
\text { deflated by the Harmonized } \\
\text { Index of Consumer Prices }\end{array}$ \\
\hline HICP & $\begin{array}{l}\text { 2010=100; all categories } \\
\text { of goods included }\end{array}$ \\
\hline ind & $\begin{array}{l}\text { Industrial production index; } \\
2010=100\end{array}$ \\
STOXX600 & $\begin{array}{l}\text { Stock index of } 600 \\
\text { companies from } 17 \\
\text { developed European } \\
\text { economies }\end{array}$ \\
\hline
\end{tabular}

oil

Brent Europe; in USD

ind $^{*}$

Industrial production index; $2010=100$

int*

3-month money market

$B B D, R$ index, interest rate (EURIBOR)
PI6, nature

and polit

dis_4, dis_7

and $d i s \_8$

Disagreement indicators $-$

dis_agr
Uncertainty indicators

Description

3-month money market interest rate (ZIBOR) deflated by the Harmonized $2010=100$; all categories ds included

\begin{tabular}{|c|c|}
\hline Time span & Source \\
\hline \multirow{8}{*}{2002 M11 - 2016 M12 } & Eurostat \\
\hline & Eurostat \\
\hline & Eurostat \\
\hline & Eurostat \\
\hline & $\begin{array}{l}\text { Thomson } \\
\text { Reuters } \\
\text { database }\end{array}$ \\
\hline & $\begin{array}{c}\text { U.S. Energy } \\
\text { Information } \\
\text { Administration }\end{array}$ \\
\hline & Eurostat \\
\hline & Eurostat \\
\hline 2002 M11 - 2016 M12 & $\begin{array}{l}\text { Authors' } \\
\text { calculation }\end{array}$ \\
\hline 2005 M05 - 2016 M12 & $\begin{array}{c}\text { European } \\
\text { Commission }\end{array}$ \\
\hline 2008 M05 - 2016 M12 & $\begin{array}{c}\text { European } \\
\text { Commission }\end{array}$ \\
\hline
\end{tabular}

$$
\frac{2005 \text { M05 - 2016 M12 }}{2008 \text { M05-2016 M12 }}
$$




\section{REFERENCES}

1. Ajmi, A. N. [et al.], 2015. Causality between US economic policy and equity market uncertainties: Evidence from linear and nonlinear tests. Journal of Applied Economics, 18(2), pp. 225-246. doi: 10.1016/S1514-0326(15)30010-6

2. Arčabić, V., 2015. Djelovanje neizvjesnosti na bankarsko tržište u Republici Hrvatskoj. EFZG Working Paper Series, No. 15-03. Available at: $<$ https:// hrcak.srce.hr/file/203426>.

3. Bachmann, R. and Bayer, C., 2013. 'Wait-and-see' business cycles?. Journal ofMonetaryEconomics, 60(6),pp. 704-719.doi: 10.1016/j.jmoneco.2013.05.005

4. Bachmann, R., Elstner, S. and Sims, E. R., 2013. Uncertainty and Economic Activity: Evidence from Business Survey Data. American Economic Journal: Macroeconomics, 5(2), pp. 217-249. doi: 10.1257/mac.5.2.217

5. Baker, S., Bloom, N. and Davis, S. J., 2012. Measuring Economic Policy Uncertainty. University of Chicago and Stanford University. Available at: $<$ www.policyuncertainty.com>.

6. Baker, S., Bloom, N. and Davis, S. J., 2016. Measuring Economic Policy Uncertainty. Quarterly Journal of Economics, 131(4), pp. 1593-1636. doi: 10.1093/qje/qjw024

7. Bejaković, P., 2009. Tax evasion, state capacity and trust in transitional countries: the case of Croatia. Društvena istraživanja, 18(4-5), pp. 787-805.

8. Belongia, M. T. and Ireland, P. N., 2016. The evolution of U.S. monetary policy: 2000-2007. Journal of Economic Dynamics and Control, 73(C), pp. 78-93. doi: 10.1016/j.jedc.2016.09.009

9. Bernanke, B., 1983. Irreversibility, Uncertainty, and Cyclical Investment. Quarterly Journal of Economics, 98(1), pp. 85-106. doi: 10.2307/1885568

10. Bloom, N., 2009. The impact of uncertainty shocks. Econometrica, 77(3), pp. 623-685. doi: 10.3982/ECTA6248

11. Bloom, N., 2014. Fluctuations in Uncertainty. Journal of Economic Perspectives, 28(2), pp. 153-176. doi: 10.1257/jep.28.2.153

12. Carroll, C. D., 1992. The buffer stock theory of saving: some macroeconomic evidence. Brookings Papers on Economic Activity, 23(2), pp. 61-155. doi: $10.2307 / 2534582$

13. CNB, 2015. Annual Report 2014. Zagreb: Croatian National Bank.

14. Cogley, T. and Sargent, T. J. 2005. Drifts and Volatilities: Monetary Policies and Outcomes in the Post WWII US. Review of Economic Dynamics, 8 (2), pp. 262-302. doi: 10.1016/j.red.2004.10.009

15. Čučković, N. and Bartlett, W., 2007. Entrepeneurship and Competitiveness: The Europeanisation of Small and Medium-sized Enterprise Policy in Croatia. Southeast European and Black Sea Studies, 7(1), pp. 37-56. doi: $10.1080 / 14683850701189311$

16. De Finetti, B., 1975. Theory of probability, Vol 1. New York: Wiley.

17. Del Negro, M. and Primiceri, G. E., 2015. Time Varying Structural Vector Autoregressions and Monetary Policy: A Corrigendum. Review of Economic Studies, 82(4), pp. 1342-1345. doi: 10.1093/restud/rdv024 
18. Dumičić, M. and Krznar, I., 2013. Financial Conditions and Economic Activity. CNB Istraživanja, I-40. Available at: <https://www.hnb.hr/documents/ 20182/121663/i-040.pdf/e1e49e05-ab3d-4426-ac41-9f00eb6d0e6d>.

19. European Commission, 2014. The joint harmonised EU programme of business and consumer surveys (user guide). Available at: <http://ec.europa.eu/ economy_finance/db_indicators/surveys/documents/bcs_user_guide_en.pdf $>$.

20. Fountas, S., Karanasos, M. and Kim, J., 2006. Inflation uncertainty, output growth uncertainty and macroeconomic performance. Oxford Bulletin of Economics and Statistics, 68(3), pp. 319-343. doi: 10.1111/j.1468-0084.2006. 00164.x

21. Garner, A. C., 1991. Forecasting consumer spending: should economists pay attention to consumer confidence surveys?. Federal Reserve Bank of Kansas City Economic Review, May/June, pp. 57-71.

22. Gemius Audience, 2017. Croatia Domains Reports. Available at: <https:// rating.gemius.com/hr/domains $>$.

23. Girardi, A. and Reuter, A., 2016. New uncertainty measures for the euro area using survey data. Oxford Economic Papers, 69(1), pp. 278-300. doi: 10.1093/ oep/gpw058

24. Grossarth-Maticek, J. and Mayr, J., 2008. Medienberichte als Konjunkturindikator. Ifo Schnell-dienst, 61, pp. 17-29.

25. Iselin, D. and Siliverstovs, B., 2013. The R-word index for Switzerland. Applied Economics Letters, 20 (11),pp. 1032-1035. doi: 10.1080/13504851.2013.772290

26. Iselin, D. and Siliverstovs, B., 2016. Using newspapers for tracking the business cycle: a comparative study for Germany and Switzerland. Applied Economics, 48(12), pp. 1103-1118. doi: 10.1080/00036846.2015.1093085

27. Jurado, K., Ludvigson, S. C. and Ng, S., 2015. Measuring Uncertainty. American Economic Review, 105(3), pp. 1177-1216. doi: 10.1257/aer.20131193

28. Karnizova, L. and Li, J., 2014. Economic policy uncertainty, financial markets and probability of US recessions. Economics Letters, 125(2), pp. 261-265. doi: 10.1016/j.econlet.2014.09.018

29. Knight, F. H., 1921. Risk, Uncertainty, and Profit. Boston, MA: Hart, Schaffner \& Marx, Houghton Mifflin Company.

30. Kramer, M. [et al.], 2008. Central Bank Communication and Monetary Policy: A Survey of Theory and Evidence. Journal of Economic Literature, 46(4), pp. 910-945. doi: /10.1257/jel.46.4.910

31. Krüger, F. and Nolte, I., 2016. Disagreement versus uncertainty: Evidence from distribution forecasts. Journal of Banking \& Finance, 72 (Supplement), pp. S172-S186. doi: 10.1016/j.jbankfin.2015.05.007

32. Krznar, I. and Kunovac, D., 2010. Impact of external shocks on domestic inflation and GDP. CNB Working Papers 26. Available at: <http://nbhnetra.hnb. $\mathrm{hr} /$ publikac/istrazivanja/w-026.pdf>. 
33. Krznar, I., 2011. Identifying Recession and Expansion Periods in Croatia. CNB Istraživanja I-32. Available at: <http://www.hnb.hr/documents/20182/ 121360/i-032.pdf/93bf31ee-0380-4e69-ac3a-175362f30884>.

34. Lütkepohl, H. and Krätzig, M., 2004. Applied Time Series Econometrics. Cambridge: Cambridge University Press. doi: 10.1017/CBO9780511606885

35. Lütkepohl, H., 2005. New Introduction to Multiple Time Series Analysis. Berlin: Springer-Verlag. doi: 10.1007/978-3-540-27752-1

36. Mačkić, V., 2014. Political budget cycles at the municipal level in Croatia. Financial Theory and Practice, 38(1), pp. 1-35. doi: 10.3326/fintp.38.1.1

37. Mihaljek, D., 2009. The Global Financial Crisis and Fiscal Poliy in Central and Eastern Europe: the 2009 Croatian Budget Odyssey. Financial Theory and Practice, 33(3), pp. 239-272.

38. Primiceri, G. E., 2005. Time Varying Structural Vector Autoregressions and Monetary Policy. Review of Economic Studies, 72(3), pp. 821-852. doi: 10.1111/j.1467-937X.2005.00353.X

39. The Economist, 2002. The recession index: Words that can harm you. The Economist, November 21. Available at: <http://www.economist.com/node/ 1455116>.

40. Vujčić, B., 2016a. Polugodišnja informacija o financijskom stanju, stupnju ostvarenja stabilnosti cijena i provedbi monetarne politike za drugo polugodište 2015. godine. Sjednica Hrvatskog sabora, 4 November 2016.

41. Vujčić, B., 2016b. Gospodarski izgledi i monetarna politika. 24. savjetovanje Hrvatskog društva ekonomista “Ekonomska politika Hrvatske u 2017.", Opatija, 9 November 2016.

42. Zrinušić, Z. and Vuraić Kudeljan, M., 2016. Porezna reforma. Porezni vjesnik, 12 , pp. 26-43. 